\title{
Comparison of High-Fidelity Computational Tools for Wing Design of a Distributed Electric Propulsion Aircraft
}

\author{
Karen A. Deere*, Sally A. Viken ${ }^{*}$, Melissa B. Carter ${ }^{\dagger}$, Jeffrey K. Viken ${ }^{\ddagger}$, Joseph M. Derlaga ${ }^{\S}$, \\ NASA Langley Research Center, Hampton, VA 23681, USA \\ Alex M. Stoll ${ }^{* *}$ \\ Joby Aviation, Santa Cruz, California, 95060, USA
}

\begin{abstract}
A variety of tools, from fundamental to high order, have been used to better understand applications of distributed electric propulsion to aid the wing and propulsion system design of the Leading Edge Asynchronous Propulsion Technology (LEAPTech) project and the X-57 Maxwell airplane. Three highfidelity, Navier-Stokes computational fluid dynamics codes used during the project with results presented here are FUN3D, STAR-CCM+, and OVERFLOW. These codes employ various turbulence models to predict fully turbulent and transitional flow. Results from these codes are compared for two distributed electric propulsion configurations: the wing tested at NASA Armstrong on the Hybrid-Electric Integrated Systems Testbed truck, and the wing designed for the X-57 Maxwell airplane. Results from these computational tools for the high-lift wing tested on the Hybrid-Electric Integrated Systems Testbed truck and the X-57 high-lift wing presented compare reasonably well. The goal of the X-57 wing and distributed electric propulsion system design achieving or exceeding the required $C_{L}=3.95$ for stall speed was confirmed with all of the computational codes.
\end{abstract}

Nomenclature

\begin{tabular}{|c|c|c|c|}
\hline & & Symbots & \\
\hline$C_{D}$ & drag coefficient & $\alpha$ & angle of attack, degrees \\
\hline$C_{D, \text { pylons }}$ & drag coefficient, pylons contribution & $\Delta$ & delta \\
\hline$C_{D, \text { wing }}$ & drag coefficient, wing contribution & & \\
\hline$C_{D, T N}$ & drag coefficient, tip nacelles contribution & Acronyms & \\
\hline$C_{D, H N L}$ & drag coefficient, high-lift nacelles contribution & BSL & Menter $k-\omega$ basic turbulence model \\
\hline$C_{L}$ & lift coefficient & CFL & $\begin{array}{l}\text { pseudo time advancement Courant- } \\
\text { Friedrichs-Lewy }\end{array}$ \\
\hline$C_{L, e f f}$ & effective lift coefficient: $C_{L}+C_{L, \text { prop }}$ & DEP & distributed electric propulsion \\
\hline$C_{L, \max }$ & maximum lift coefficient & HLN & high-lift nacelles \\
\hline$C_{L, \text { prop }}$ & lift coefficient from the contribution of & KCAS & knots calibrated airspeed \\
\hline & propeller thrust in lift direction & KEAS & knots equivalent airspeed \\
\hline$C_{m}$ & pitching moment coefficient & KTAS & knots true airspeed \\
\hline$C_{p}$ & pressure coefficient & LM & Langtry-Menter transition model \\
\hline$C_{\text {ref }}$ & reference chord, ft & mph & miles per hour \\
\hline $\mathrm{h}$ & altitude, $\mathrm{ft}$. & QCR & quadratic constitutive relation \\
\hline$M$ & Mach number & RPM & revolutions per minute \\
\hline $\mathrm{P}$ & pressure, $1 \mathrm{bf} / \mathrm{in}^{2}$ & SA & $\begin{array}{l}\text { Spalart-Almaras one equation } \\
\text { turbulence model }\end{array}$ \\
\hline $\operatorname{Re}$ & Reynolds number based on $C_{r e f}$ & SARC & SA rotation and curvature correction \\
\hline $\mathrm{S}$ & wing area, $\mathrm{ft}^{2}$ & SHP & shaft horse power \\
\hline $\mathrm{T}$ & temperature, ${ }^{\circ} \mathrm{F}$ & SST & Menter's Shear Stress Transport model \\
\hline W & aircraft weight, $\mathrm{lb}$ & $\mathrm{TN}$ & tip nacelles \\
\hline
\end{tabular}

* Aerospace Engineer, Configuration Aerodynamics Branch, Mail Stop 499, AIAA Senior Member

† Aerospace Engineer, Configuration Aerodynamics Branch, Mail Stop 499, AIAA Associate Fellow

₹ Aerospace Engineer, Aeronautics Systems Analysis Branch, Mail Stop 442, AIAA Senior Member

$\S$ Research Scientist, Computational AeroSciences Branch, Mail Stop 128, AIAA Member

${ }^{* *}$ Aeronautical Engineer, 340 Woodpecker Ridge, AIAA Member. 


\section{Introduction}

NASA has restarted its X-plane research approach to demonstrating advanced airplane technology. The X-57 Maxwell, or Scalable Convergent Electric Propulsion Technology and Operations Research (SCEPTOR) airplane, will be the first of several airplanes to push to new frontiers of flight. One goal of the all-electric X-57 Maxwell technology demonstrator is to prove that significantly reducing wing area (to improve cruise efficiency) can be done without reducing takeoff and landing performance by application of distributed electric propulsion (DEP) to effect a blown wing.

For this X-plane demonstrator, the new DEP wing system will be installed on a Tecnam P2006T aircraft (fig. 1) by removing the original wing and installing the cruise-optimized DEP wing (fig. 2). The main performance goals are a 58 KEAS stall speed at $3000 \mathrm{lb}$ gross weight (scaled from the original P2006T gross weight and stall performance), equating to a $C_{L}=3.95$, while achieving a cruise speed of 150 KTAS at 8,000 feet with 5 times lower energy use than the original P2006T. This performance should be achieved with the increased propulsion system efficiency of the electric motor/battery system. The sizing design study of the wing presented in Reference 1 resulted in a wing design with a wing loading of 45 $\mathrm{lb} / \mathrm{ft}^{2}$, a wing area of $66.67 \mathrm{ft}^{2}$, an aspect ratio of 15 , and a cruise $C_{L}=0.75$. The higher aspect ratio for the new wing is meant to minimize induced drag at cruise, since the new wing's cruise lift coefficient is much higher than the original P2006T. The original P2006T has a wing loading of $16.365 \mathrm{lb} / \mathrm{ft}^{2}$, a wing area of $158.88 \mathrm{ft}^{2}$, an aspect ratio of 8.8 , and a cruise $C_{L}=0.275$. The specially designed X-57 airfoil is tailored for a cruise lift coefficient of 0.85 and incorporates a $25 \%$ chord flap. The flap design uses a single-pivot displaced hinge with a $30^{\circ}$ maximum deflection. To achieve the X-57 stall speed goal, a $C_{L, \max }=3.95$ is required from the wing and DEP high-lift system.

The project began with the intent to use computational tools to design the X-57 Maxwell wing. Low fidelity tools were used to create the basic design, with checks and course corrections done with selected runs of higher-order codes. A variety of tools and their many uses in the aspects of the aero-propulsive design were documented in Reference 2. This paper will discuss the comparison of results from several high-fidelity computational tools used in the effort to investigate the viability of distributed electric propulsion and to validate the results of the low-fidelity tools used to design the X-57 Maxwell wing, and will focus on the high-lift wings with the flap extended. Not all tools were used for all the conditions and all the configurations. Instead, different problems were investigated with the various, established tools, familiar to the users who implemented the best practices of those tools to build the large database of information.

\section{Configurations}

Four configurations were used for comparing computational fluid dynamics (CFD) tools in this project. The first configuration was the wing on the Hybrid-Electric Integrated Systems Testbed (HEIST) truck as shown in figure 3(a) and is represented with a computational model of the right semispan wing in figure 3(b). The wing was tested on the HEIST truck at NASA Armstrong as part of the Leading Edge Asynchronous Propulsion Technology (LEAPTech) project [3]. The LEAPTech wing had $4^{\circ}$ of twist and the $\alpha=0^{\circ}$ is when the root section incidence is $5^{\circ}$. The second configuration was the X-57 Maxwell cruise wing with high-lift and wing-tip cruise motor nacelles as shown in figure 4(a). The third and fourth configurations were the X-57 Maxwell wing with $30^{\circ}$ flap and wing-tip cruise motor nacelles, both with and without high-lift nacelles, and are shown in figures 4(b) and 4(c), respectively. The X-57 wing has $2^{\circ}$ of twist and the CFD $\alpha=0^{\circ}$ is when the root section incidence is $2^{\circ}$.

The LEAPTech blown-wing configuration had 18 high-lift propellers mounted on nacelles upstream of the wing leading edge. The propeller positions were staggered longitudinally to follow the sweep in the wing leading edge as shown in Figure 3. The data in this paper focused on the configuration with a $40^{\circ}$ flap setting. Figure 3(b) shows two black lines where spanwise data was extracted from the CFD solution. Stations 1 and 2 are approximately 3 inches and 8 inches downstream of the leading edge, respectively. The experimental data from the HEIST test was not of sufficient quality to validate CFD data because of the uncertainty associated with this new truck-test technique. Since no previous DEP experiments have been conducted, the LEAPTech data was used to qualitatively compare with the CFD solutions to gain confidence that the tools could predict powered lift increments comparable to those seen in the HEIST experiment. In addition, the LEAPTech wing configuration was used for CFD code comparisons and was used as a confidence building study of the advanced tools. 
The X-57 Maxwell wing has been through several design improvement revisions. The X-57 cruise and high-lift, blown-wing configurations that are presented in this paper is the 4.1 design revision. The blownwing configuration with a $30^{\circ}$ flap setting, had 12 high-lift propellers mounted on nacelles upstream of the wing leading edge. The X-57 propellers were positioned in an alternating fore- and aft-staggered pattern as shown in figures 4(a) and 4(b). A black line is added to figure 4(a) to illustrate the staggered pattern of the nacelles. Figure 4(c) shows the high-lift, blown-wing configurations without the high-lift nacelles (HLN), used to investigate the impact of the pylon and nacelle geometry on wing performance.

\section{High-Fidelity Distributed Propulsion Analysis Tools}

Three Navier-Stokes CFD codes have been used to investigate the DEP systems on the LEAPTech and X-57: FUN3D, STAR-CCM+, and OVERFLOW, with various turbulence models. A variety of modeling approaches were used for the high-lift propellers, including actuator disks in FUN3D and STAR-CCM+, and rotating propellers in OVERFLOW.

\section{A. FUN3D}

FUN3D [4] is a node-based, finite-volume discretization, Reynolds-averaged Navier-Stokes flow solver. All solutions were computed as fully-turbulent flow. All of the FUN3D simulations for this study used an actuator disk representation for the high-lift propellers, with thrust and torque coefficient data input into the system. The thrust and torque coefficient data was derived from the XROTOR [5] blade element momentum analyses.

\section{Grid Generation}

An unstructured, mixed element mesh was used for the FUN3D simulations. The mixed element mesh had prisms in the boundary layer, tetrahedral cells in the far field, and pyramids to transition between the boundary layer and far-field cells.

The semispan mesh for the LEAPTech wing had 42.9 million mesh points. The farfield boundaries were extended to approximately 100 chord lengths away from the wing. A flat-plate, turbulent boundary layer calculator was used with Reynolds number based on reference chord length, chord length, intended $\mathrm{y}^{+}$, and an intended number of boundary layers to determine the input for the first node height and expansion rate of the grid in VGRID. As recommended in reference 6, the intended $\mathrm{y}^{+}$used was 0.67 for a medium mesh resolution, and the number of boundary layers was specified as 26 . The corresponding VGRID spacing for the first node height was $2.8 \mathrm{e}-4 \mathrm{in}$. The boundary layer specifications were good for the unblown wing (not shown in this paper) because the solutions had $\mathrm{y}^{+}$of 1 or less. However, for the blownwing cases, the $\mathrm{y}^{+}$varied; with values of 1 in the unblown region, values of 1.5 on the wing upper surface in the blown region, and values of 2 on the wing leading edge.

The semispan mesh for the X-57 cruise wing with tip nacelles (no HLN) had 43.9 million mesh points. The semispan mesh for the cruise wing with high-lift and tip nacelles had 47.9 million mesh points. The semispan mesh for the X-57 high-lift wing $30^{\circ}$ flap, with high-lift nacelles, and tip nacelles along with additional clustering in the regions of the propellers had 153 million mesh points. The farfield boundaries were extended to approximately 110 chord lengths away from the wing. A smaller intended $\mathrm{y}^{+}$and more boundary layers were used for the X-57 wing because the $\mathrm{y}^{+}$was higher than 1 for the blown-wing LEAPTech configuration. Therefore, the intended $\mathrm{y}^{+}$value used in the flat-plate, turbulent boundary layer calculator was $\mathrm{y}^{+}=0.3$, as recommended for an extra fine mesh resolution [6]. The expansion rate was set by specifying 32 layers of cells within the boundary layer. Data from the cruise wing solutions and the high-lift wing without power show that $\mathrm{y}^{+}$was less than 0.7 for all angles of attack. For the high-lift wing with high-lift power cases, the $\mathrm{y}^{+}$from the solutions varied up to 1.5 on the wing leading edge.

\section{Computational Flow Solver and Solution Procedure}

The low and moderate angle of attack cases were run with steady state calculations that used a local time step pseudo-time advancement scheme. The pseudo time advancement Courant-Friedrichs-Lewy (CFL) number was ramped up from 1 to 100 over 1000 iterations for lower angles of attack, and the maximum CFL number was limited to 40 for the higher angles of attack. At higher angles of attack, an optimized second-order backward differencing scheme was used for time-accurate temporal time integration. The Spalart-Allmaras turbulence model [7] was used with the rotation and curvature (RC) corrections, and the mean stress-strain Quadratic Constitutive Relationship (QCR) [8]. The Menter $k-\omega$ 
baseline (BSL) model [9] was used for some X-57 wing analyses to determine the effect of the turbulence model on wing performance and flow separation.

3. Convergence Criteria

The criteria used to monitor and determine solution convergence was a drop of at least two orders of magnitude for the mean flow solution residual, along with a standard deviation of less than 0.0012 for the lift coefficient and 0.0002 for the drag coefficient, over 1000 iterations. If a steady state solution did not meet the convergence criteria, the solutions were then computed with the time accurate method of a global time step.

\section{B. STAR-CCM+}

STAR-CCM+ [10-12] is an unstructured cell-centered finite-volume-based solver. It was used for a variety of steady Reynolds-Averaged Navier-Stokes simulations.

\section{Grid Generation}

The meshing model employed a template mesh constructed from hexahedral cells, from which it cut or trimmed the core mesh based on the starting input surface. The resulting mesh was composed predominantly of hexahedral cells with trimmed cells next to the surface. A robust automated prism layer meshing algorithm was used to capture the boundary layer, with wall $\mathrm{y}^{+}$values kept below approximately one. Mesh refinement was defined in regions such as the gap between the flap and the main element of the wing, around the propeller disks and streamtubes, and around wingtip vortices.

For the LEAPTech configuration, the computational domain was a cylinder aligned with the longitudinal axis of the wing with a radius of about 9 wingspans, which extended 5 wingspans upstream of the wing and approximately 11 wingspans downstream.

For the X-57 configuration, the computational domain was a hemisphere with radius of about 19 wingspans with the flat face oriented normal to the longitudinal axis of the wing and located about 13 wingspans downstream of the wing, placing the front of the hemisphere about 6 wingspans upstream of the wing.

\section{Computational Flow Solver and Solution Procedure}

Turbulence closure was achieved using the SST Menter $k-\omega$ model $[9,13]$, with transition modeled by the correlation-based $\gamma-\operatorname{Re}_{\theta}$ model [14-15].

To decrease the computational expense of these simulations, instead of resolving the full geometry of the propeller, the propellers were modeled with an actuator disk, by prescribing uniform volume force distributions over cylindrical virtual disks. In the LEAPTech analyses, the volume forces varied in the radial direction, with the radial distribution of the force components based on the optimal Goldstein distribution, as described by Stern et al. [16]. The thrust and power were calculated from XROTOR, with the implicit assumption that these values do not change substantially when the propellers are operated upstream of the wing, and that the propeller normal force is negligible at the angles of attack of interest. The X-57 analyses employed a similar model, with the assumed radial force distribution substituted with a model combining a blade-element method, with velocities calculated from local flow conditions. This model captured variations of thrust and normal force with angle of attack, and the azimuthal variation of thrust and torque.

\section{Convergence Criteria}

The criteria used to monitor and determine solution convergence was based on the settling of parameters of interest, such as lift, pressure drag, and shear drag, for at least 300 iterations; however, this number of iterations varied with the type of simulation.

\section{OVERFLOW}

Simulations on structured, overset grids were performed using the OVERFLOW [17] solver. Due to the use of overset grids, various buildups of the X-57 baseline wing were studied, including the addition of cruise wing-tip and high-lift nacelles. In addition, overset grids allowed for rigid body motion simulations of the cruise and high-lift propellers in isolation and installed on the X-57 geometry. 


\section{Grid Generation}

Near-body meshes were generated using the Chimera Grid Tools suite [18]; surface meshes were based on PLOT3D files directly exported from OpenVSP. The volume meshes were designed for a minimum viscous wall spacing requirement of $\mathrm{y}^{+} \leq 1.0$, with five constant layers of growth off the viscous walls, and at least three layers of node overlap between adjoining grids. OVERFLOW-D mode was used (Domain Connectivity Function, or DCF), which enabled Cartesian off-body grids to be automatically generated by OVERFLOW extending approximately 100 chord lengths away from the wing.

\section{Computational Flow Solver and Solution Procedure}

A fifth-order WENO5M scheme [19] was used to perform variable reconstruction for the HLLE++ inviscid flux scheme [20], and a second-order central scheme was used for the viscous fluxes. Fully turbulent solutions were performed using a Spalart-Allmaras turbulence model, specifically SA-noft2-RCQCR2000 (Rotation Correction with Quadratic Constitutive Relationship) [8, 21]. Results including transition were obtained using a k- $\omega$ SST-RC-QCR2000 turbulence model [7, 9] in conjunction with the Langtry-Menter CFX-v-1.1 transition model [14].

Euler implicit time marching was used to reach a steady-state solution for nonmoving body simulations near cruise conditions. A second-order implicit time advancement method was used for moving body simulations, or near stall conditions. At least two orders of magnitude of convergence was desired per time step for unsteady simulations. For unsteady runs without propellers, at least 20,000 physical time steps were taken, given a time step based on the time required for a fluid particle to move $3 \mathrm{~cm}$. For propeller cases, an initial time step based on $1 / 4$ degree of rotation of the propeller was used, but this was relaxed to 1 degree of rotation per time step to speed convergence to a pseudo-steady state solution without undue change to force and torque predictions. For cases with installed high-lift propellers, four degrees per time step was used in order to quickly propagate the propeller wakes to the farfield. In general, at least 16 revolutions were used to complete the calculations for the installed, high-lift propeller cases.

\section{Convergence Criteria}

Besides the unsteady convergence requirements noted above, steady state forces were examined for standard deviations of less than 0.0001. For steady simulations, forces and moments were typically averaged over the last 1,000 iterations. Unsteady simulations without propellers were averaged over the time to traverse one mean aerodynamic chord length, while simulations with propellers were averaged over the time to complete one revolution.

\section{Conditions}

The LEAPTech configuration studies were conducted at $\mathrm{h}=2300 \mathrm{ft}$, the altitude of the NASA Armstrong Flight Research Center, with the freestream flow at $40 \mathrm{mph}, 60 \mathrm{mph}$ and $73 \mathrm{mph}$. This paper focuses on data at $63.4 \mathrm{KTAS}(73 \mathrm{mph}, M=0.0977), \mathrm{T}=40^{\circ} \mathrm{F}, C_{\text {ref }}=1.6 \mathrm{ft}$, and $\mathrm{Re}=1.07 \mathrm{million}$. The angle-of-attack sweep was from $\alpha=0^{\circ}$ to $\alpha=18^{\circ}$. The high-lift power settings were 6860 RPM for landing (equivalent to $18 \mathrm{shp} / \mathrm{prop}$ ) and $6370 \mathrm{RPM}$ for take-off (equivalent to $14.3 \mathrm{shp} / \mathrm{prop}$ ). All cases were analyzed with a $40^{\circ}$ flap setting.

For the X-57 configuration, landing (58 KTAS) and cruise (150 KTAS) conditions were investigated. The landing stall condition $\left(30^{\circ}\right.$ flap setting) was for a speed of 58 KTAS $(66.7 \mathrm{mph}, M=0.0878)$ at sea level conditions with $\mathrm{T}=59^{\circ} \mathrm{F}, \mathrm{h}=0 \mathrm{ft}, C_{\text {ref }}=2.13 \mathrm{ft}, \mathrm{Re}=1.33$ million, and with a range of angle of attack from $\alpha=0^{\circ}$ to $\alpha=18^{\circ}$. The cruise condition was for a speed of $150 \mathrm{KTAS}(172.6 \mathrm{mph}, M=0.233)$ at an altitude of $\mathrm{h}=8000 \mathrm{ft}, \mathrm{T}=30.5^{\circ} \mathrm{F}, \mathrm{Re}=2.83$ million, and computed for a range of angle of attack from $\alpha=-4^{\circ}$ to $\alpha=18^{\circ}$. For the solutions presented the calculations did not include cruise power in the wing-tip propeller.

\section{Results}

Figure 5 shows the performance comparisons between FUN3D and STAR-CCM+ for the LEAPTech DEP wing with $40^{\circ}$ flap setting. The lift coefficient compares very well between the codes for the unblown (no power) wing, and for the two blown-wing, power conditions with both codes modeling the propellers with an actuator disk model. Some differences between the code results are expected because the STAR$\mathrm{CCM}+$ results predict some laminar flow with the $\gamma-\mathrm{Re}_{\theta}$ transition model, while the FUN3D results are fully-turbulent flow predictions. The FUN3D SARC+QCR results predict the maximum lift coefficient at 
$\alpha=4^{\circ}$ for both the $14.3 \mathrm{shp} / \mathrm{prop}$ and the $18 \mathrm{shp} /$ prop power conditions, where the propeller blowing generates the most lift with the lowest pressures above the wing. Both codes show good comparison of the increase in lift due to high-lift power for the two power settings of $14.3 \mathrm{shp} / \mathrm{prop}$ (6370 RPM) and 18 shp/prop (6860 RPM). The maximum high-lift power setting has a $C_{L, \max }=5.61$, a factor of 2.5 times the power-off $C_{L, \max }$.

The pressure coefficient from FUN3D for the LEAPTech wing at station 1 (fig. 3(b)) for angles of attack $4^{\circ}$ and $8^{\circ}$ at the $18 \mathrm{shp} /$ prop (6860 RPM) power condition is shown in figure 6 . At $\alpha=4^{\circ}$, there are low-pressure regions of $C_{p}=-4$ above the wing, at all of the nacelles. Above $\alpha=4^{\circ}$, the FUN3D code predicts a slight drop in lift coefficient for both the $14.3 \mathrm{shp} /$ prop and the $18 \mathrm{shp} /$ prop power conditions, as the flow separates from the upper surface of the wing between nacelles 7 and 8 ; this is shown as a reduction of the low-pressure region above the wing at $\alpha=8^{\circ}$ (fig. 6(b)). The change in pressures between nacelles 7 and 8 can be further visualized in figure 7 by comparing the outboard upper surface pressure coefficient between $\alpha=4^{\circ}$ and $\alpha=8^{\circ}$. STAR-CCM+ predicts a similar trend as FUN3D for the $14.3 \mathrm{shp} / \mathrm{prop}$ power condition (fig. 5), with a similar maximum lift coefficient, but at a higher angle of attack $\left(7^{\circ}\right)$, followed by a slight drop in lift with increasing $\alpha$. Figure 8 shows the pressure coefficient from STAR-CCM+ for the LEAPTech wing at station $1, \alpha=4^{\circ}$ and $\alpha=10^{\circ}$, with $14.3 \mathrm{shp} /$ prop (6370 RPM) power condition. The effect of the blown wing is evident with the low-pressure region along the full span for $\alpha=4^{\circ}$ (fig. 8(a)), resulting in a lift coefficient of $C_{L}=5.15$, compared to the unblown $C_{L}=2.09$ (fig. 5). STAR-CCM+ predicts the flow separation associated with the loss in lift at $\alpha=10^{\circ}$ to occur further inboard than FUN3D, between nacelles 5 and 6 (fig. 8(b)). For the 18 shp/prop (6860 RPM) power condition, STAR-CCM+ predicts an increase in $C_{L}$ with an increase of angle of attack from $1^{\circ}$ to $10^{\circ}$ and maximum lift is not yet determined (fig. 5).

For the solutions of the X-57 configuration, grids with and without the HLN were generated to determine the impact of the high-lift nacelles on wing performance. Additionally, without the HLN, the complexity of the configuration is reduced, making it a good configuration for comparing each of the codes' ability to predict unblown performance. Knowing how well the codes compare without the high-lift blowing provides a foundation for comparisons between more complex configurations and conditions. The comparisons of lift and drag coefficients predicted with FUN3D and STAR-CCM+ for the X-57 unblown $30^{\circ}$ flap configuration with tip nacelles, but without high-lift nacelles, are shown in figure 9 . The results from the two codes compare well, with the STAR-CCM+ transition model predicting slightly less drag due to the presence of some laminar flow on the wing compared to the fully turbulent prediction of FUN3D. Note, however, at the angle of attacks shown, the drag is dominated by pressure due to separation and induced drag.

Figure 10 shows the comparison of effective lift coefficient and drag coefficient for the X-57 high-lift power blown wing (with $30^{\circ}$ flap and HLN) for the landing conditions at $58 \mathrm{KTAS}, \mathrm{T}=59^{\circ} \mathrm{F}, \mathrm{h}=0 \mathrm{ft}$, and $\operatorname{Re}=1.33$ million. The effective lift $\left(C_{L, e f f}\right)$ is the lift of the wing predicted by the CFD solution plus the vectors of propeller thrust and normal force in the lift direction. The FUN3D and STAR-CCM+ solutions used an actuator disk to model the high-lift blowing, while OVERFLOW used moving propellers. The CFD grid for the FUN3D solution included the wing-tip nacelles, while the grids for OVERFLOW and STAR$\mathrm{CCM}+$ did not. The most important take-away from this data is that all the high-fidelity CFD tools predict that the wing achieved, and exceeded, the required $C_{L}=3.95$ to meet the stall speed goal. The break in the lift coefficient curve that indicates wing stall for FUN3D SARC+QCR, FUN3D BSL, and STARCCM+ $\gamma-$ $\operatorname{Re}_{\theta}$ model are at $13^{\circ}, 16^{\circ}$, and $13.5^{\circ}$ angles of attack, respectively. The OVERFLOW solution did not predict wing stall for the three angles of attack that were computed. The maximum lift coefficient and associated angle of attack varies between the configurations depending on the angle of attack at which the upper-surface flow separation moves forward to the wing leading edge. This is explained in the following paragraphs.

Figure 11 shows the comparison of pressure coefficient and skin friction coefficient on the X-57 wing upper surface at $\alpha=12^{\circ}$. Maximum lift occurs for FUN3D SARC+QCR at $\alpha=12^{\circ}$ (fig. 10(a)), but the magnitude of $C_{L}$ is lower than the other codes as the flow inboard does not reach the same negative $C_{p}$ values along the upper surface (fig. 11), which is more easily seen in figure 12. Figure 12 shows the comparison of pressure coefficient between the FUN3D solutions (SARC+QCR and Menter $k-\omega$ BSL) at y $=10$ in. and $\mathrm{y}=20$ in., where the centerline of the full span wing is at $\mathrm{y}=0 \mathrm{in}$. At both y locations, the Menter $k-\omega$ BSL predicts more flow expansion to lower $C_{p}$ than the SARC+QCR model. For the $\mathrm{y}=10 \mathrm{in}$. 
section, the SARC+QCR model predicts flow separation around $\mathrm{x}=167 \mathrm{in}$. or 59 percent of the chord, while the Menter $k-\omega$ BSL predicts separation further aft around $\mathrm{x}=174$ in. or about 83 percent of the chord (fig. 12(a)).

The FUN3D SARC+QCR predicts inboard flow separation (0 in. $<\mathrm{y}<23$ in.) that moves forward to the wing leading edge, decreasing lift, as angle of attack is increased to $\alpha=13^{\circ}$ (see fig. 13), while the other codes predict an increase in lift in this angle of attack range (fig. 10(a)). The change in inboard flow separation from midchord up to the leading edge for FUN3D SARC+QCR can be visualized in figures 11 (a) and 13 and noticing the large dark blue region in the skin friction coefficient that is present in the range of 0 in. $<\mathrm{y}<23$ in. at $\alpha=13^{\circ}$ (fig. 13). As angle of attack is increased, at $\alpha=14^{\circ}$, STAR-CCM+ also predicts inboard flow separation that moves forward to the leading edge, as shown in figure 14(c). Figure 15 shows the pressure coefficient and skin friction coefficient on the wing upper surface at $\alpha=16^{\circ}$, the angle at which the FUN3D Menter $k-\omega$ BSL model predicts the inboard flow separation moving forward to the wing leading edge (fig. 15(b)). Additionally, the outboard flow separation for $\alpha=16^{\circ}$ is larger than the flow separation on the wing at $\alpha=14^{\circ}$ in fig. 14(b). The change in outboard flow separation with angle of attack is further illustrated in figures 16 and 17. Figure 16 shows the skin friction coefficient in the $\mathrm{x}$ direction with a cut-off limiting value to remove reversed, separated flow from view and the wing surface shown as gray. Figure 17 shows the span locations of $y=150$ in., 160 in., 170 in., and 180 in. on the wing (fig. 17(a)), and the comparison of pressure coefficient between $\alpha=14^{\circ}$ and $\alpha=16^{\circ}$ at those span locations. The pressure coefficient distributions are identical between $\alpha=14^{\circ}$ and $\alpha=16^{\circ}$ in the blownwing region at $\mathrm{y}=150$ in. (fig. 17(b)). The flow separation predicted on the upper surface of the wing with the Menter $k$ - $\omega$ BSL turbulence model for both $\alpha=14^{\circ}$ and $\alpha=16^{\circ}$ is outboard of the blown-wing flow at $\mathrm{y}=150 \mathrm{in}$. For the $\alpha=14^{\circ}$ case, the separation ahead of the aileron is at almost a constant chord location between 150 in. $<y<180$ in. At station $y=170$ in., the separation line is at approximately 73 percent chord (fig. 17(d)), and at station $y=180$ in. the flow is again attached to the trailing edge. For $\alpha=16^{\circ}$, the separation region extends past station $y=180$ in. (fig. 17(e)) and out to the tip nacelle (fig. 16(b)). The separation location varies with span from 77 percent chord at $y=160$ in. (fig. 17(c)), to 59 percent chord at $y=170$ in. (fig. 17(d)), and to 13 percent chord at $y=180$ in. (fig. 17(e)). Flow in the blown region of the wing (excluding the flap element) remains attached over the complete upper surface for all the codes at all the data acquired.

\section{Conclusions}

Comparisons have been made between the high order computational tools used for analysis of the distributed electric propulsion systems on the LEAPTech wing and the X-57 wing. The experimental data of the LEAPTech wing from the HEIST test was not of sufficient quality to validate computational data because of the uncertainty associated with this new truck-test technique. Since no previous distributed electric propulsion experiments had been conducted, the LEAPTech data was used to qualitatively compare with the computational solutions to gain confidence that the tools could predict powered-lift increments comparable to those seen in the HEIST experiment. In addition, the LEAPTech wing geometry configuration was used for computational code comparisons and was used as a confidence building study of the advanced tools.

The computational results compare well and differences can be explained by slight geometry differences (e.g., including or excluding tip nacelle) or by differing turbulence model or propeller modeling approaches. The main difference in the X-57 high-lift wing results between various turbulence models was the prediction of inboard flow separation from 0 in. $<\mathrm{y}<23$ in. at different angles of attack. The SARC+QCR model (FUN3D) and the $\gamma-\operatorname{Re}_{\theta}$ model (STAR-CCM+) predicted inboard flow separation that moved forward to the wing leading edge at angles of attack of $13^{\circ}$ and $13.5^{\circ}$, respectively. The Menter $k$ - $\omega$ BSL model predicted inboard separation at higher angle of attack, $16^{\circ}$, and had outboard separation that moved forward to the leading edge near the tip nacelle. The OVERFLOW solution did not predict inboard flow separation up to the leading edge like the other models, for the three angles of attack that were computed. The OVERFLOW solution employed the same $\gamma-\operatorname{Re}_{\theta}$ model as STAR-CCM+, but OVERFLOW implemented rotating propellers while the STAR-CCM+ solution used an actuator disk model. However, overall, the goal of achieving or exceeding the required $C_{L}=3.95$ was confirmed with all the computational codes. 


\section{References}

1. Borer, Patterson, Viken, Moore, Clarke, Redifer, Christie, Stoll, Dubois, Bevirt, Gibson, Foster, and Osterkamp: "Design and Performance of the NASA SCEPTOR Distributed Electric Propulsion Flight Demonstrator," Aviation Forum in Washington D. C., AIAA 2016-3920, 13-17 June 2016.

2. Borer, N. K.; Derlaga, J. M.; Deere, K. A.; Carter, M. B.; Viken, S. A.; Patterson, M. D.; Litherland, B. L.; and Stoll, A.: "Comparison of Aero-Propulsive Performance Predictions for Distributed Propulsion Configurations," AIAA 2017-0209.

3. Stoll, A. M.: "Comparison of CFD and Experimental Results of the LEAPTech Distributed Electric Propulsion Blown Wing,” AIAA 2015-3188, 22-26 June 2015.

4. Biedron, R. T., Carlson, J. R.; Derlaga, J. M.; Gnoffo, P. A.; Hammond, D. P.; Jones, W. T.; Kleb, B.; Lee-Rausch, E. M.; Nielsen, E. J.; Park, M. A.; Rumsey, C. L.; Thomas, J. L.; and Wood, W. A.: "FUN3D Manual: 13.0," NASA TM-2016-219330.

5. Drela, M., and Youngren, H.: XROTOR Download Page, http://web.mit.edu/drela/Public/web/xrotor/, accessed 6 May 2014.

6. " $2^{\text {nd }}$ AIAA CFD High Lift Prediction Workshop Gridding Guidelines," http://hiliftpw.larc.nasa.gov, https://hiliftpw.larc.nasa.gov/Workshop2/GriddingGuidelines-HiLiftPW2-v2.pdf, March 2013.

7. Shur, M. L., Strelets, M. K., Travin, A. K., and Spalart, P. R.: Turbulence Modeling in Rotating and Curved Channels: "Assessing the Spalart-Shur Correction," AIAA Journal Vol. 38, No. 5, 2000, pp. 784-792.

8. Spalart, P. R.: "Strategies for Turbulence Modeling and Simulation. International Journal of Heat and Fluid Flow," Vol. 21, 2000, pp. 252-263.

9. Menter, F. R.: "Two-Equation Eddy-Viscosity Turbulence Models for Engineering Applications," AIAA Journal, vol. 32, no. 8, Aug. 1994, pp. 1598- 1605.

10. CD-Adapco, "STAR-CCM+," http://www.cd-adapco.com/products/star-ccm\%C2\%AE, accessed 23 October 2015.

11. Hanke, J.; Shankara, P.; and Snyder, D.: "Numerical Simulation of DLR-F11 High Lift Configuration from HiLiftPW-2 using STAR-CCM+," AIAA 2014-0914, 13-17 January 2014.

12. Shankara, P. and Snyder, D.: "Numerical Simulation of High Lift Trap Wing using STAR-CCM+," AIAA 2012-2920, 25-28 June 2012.

13. Durbin, P.: "On the k-3 Stagnation Point Anomaly," International Journal of Heat and Fluid Flow, 17(1):89-90, 1996.

14. Menter, F. R., Langtry, R., Likki, S., Suzen, Y., Huang, P., and Volker, S.: “A Correlation-based Transition Model Using Local Variables - Part I: Model Formulation," Journal of Turbomachinery, Vol. 128, No. 3, pp. 413-422, 2006.

15. Langtry, R.: "A Correlation-based Transition Model Using Local Variables for Unstructured Parallelized CFD Codes," Doctoral thesis, University of Stuttgart, 2006.

16. Stern, F., Kim, H., Patel, V., and Chen, H.: "A viscous-flow approach to the computation of propellerhull interaction," Journal of Ship Research, 32(4): 246-262, 1988.

17. "NASA OVERFLOW Overset Grid CFD Flow Solver," http://overflow.larc.nasa.gov/, accessed 23 October 2015.

18. "Chimera Grid Tools User's Manual," https://www .nas.nasa.gov/publications/software/docs/chimera/index.html, accessed 4 December 2016.

19. Kenrick, A. K., Aslam, T. D., and Powers, J. M.: "Mapped Weighted Essentially Non-Oscillatory Schemes: Achieving Optimal Order Near Critical Points," Journal of Computational Physics, 207:542$567,2005$.

20. Tramel, R., Nichols, R., and Buning, P. G.: "Addition of Improved Shock-Capturing Schemes to OVERFLOW 2.1," AIAA-2009-3988, 19 ${ }^{\text {th }}$ AIAA Computational Fluid Dynamics Conference, San Antonio, Texas, June 2009.

21. Eca, L., Hoekstra, M., Hay, A., and Pelletier, D.: "A Manufactured Solution for a Two-Dimensional Steady Wall-Bounded Incompressible Turbulent Flow," International Journal of Computational Fluid Dynamics, 21(3-4):175-188, 2007. 


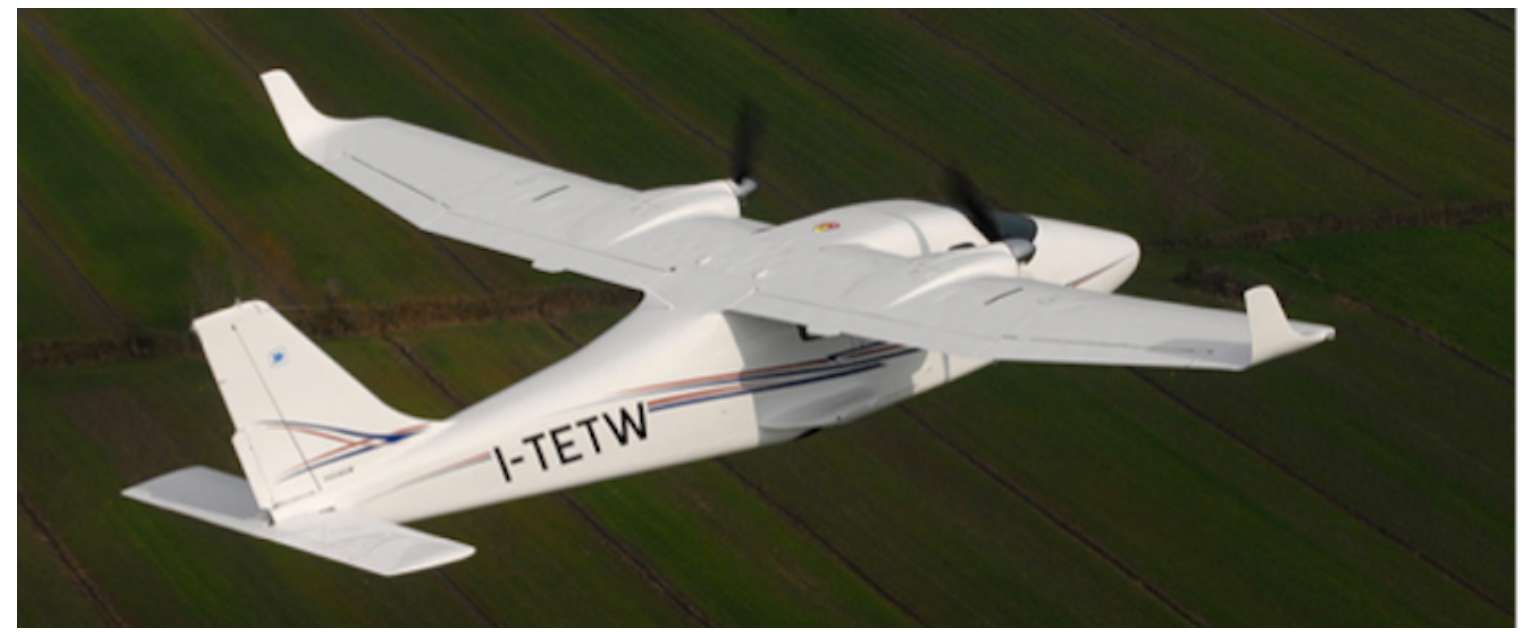

Figure 1. The original Tecnam P2006T aircraft.

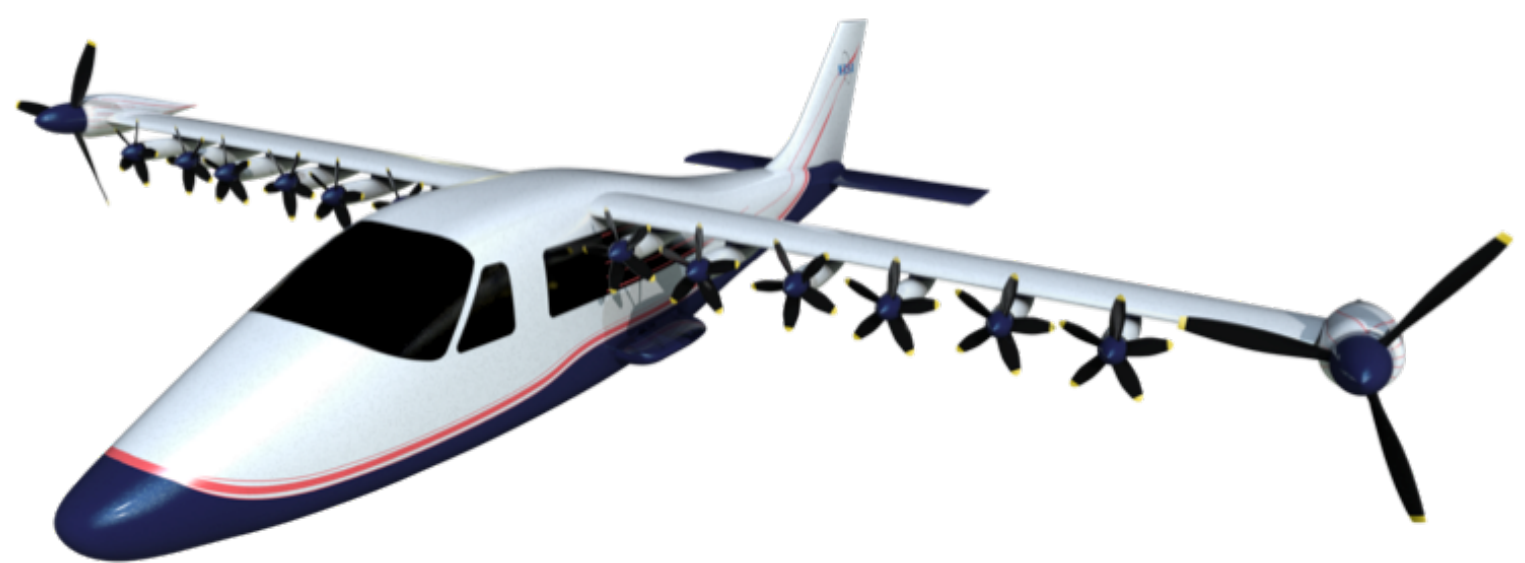

Figure 2. The X-57 Maxwell DEP aircraft. The Tecnam P2006T fuselage and tail with the DEP wing system that includes the wingtip propellers and the high-lift motors. 
Denver, CO

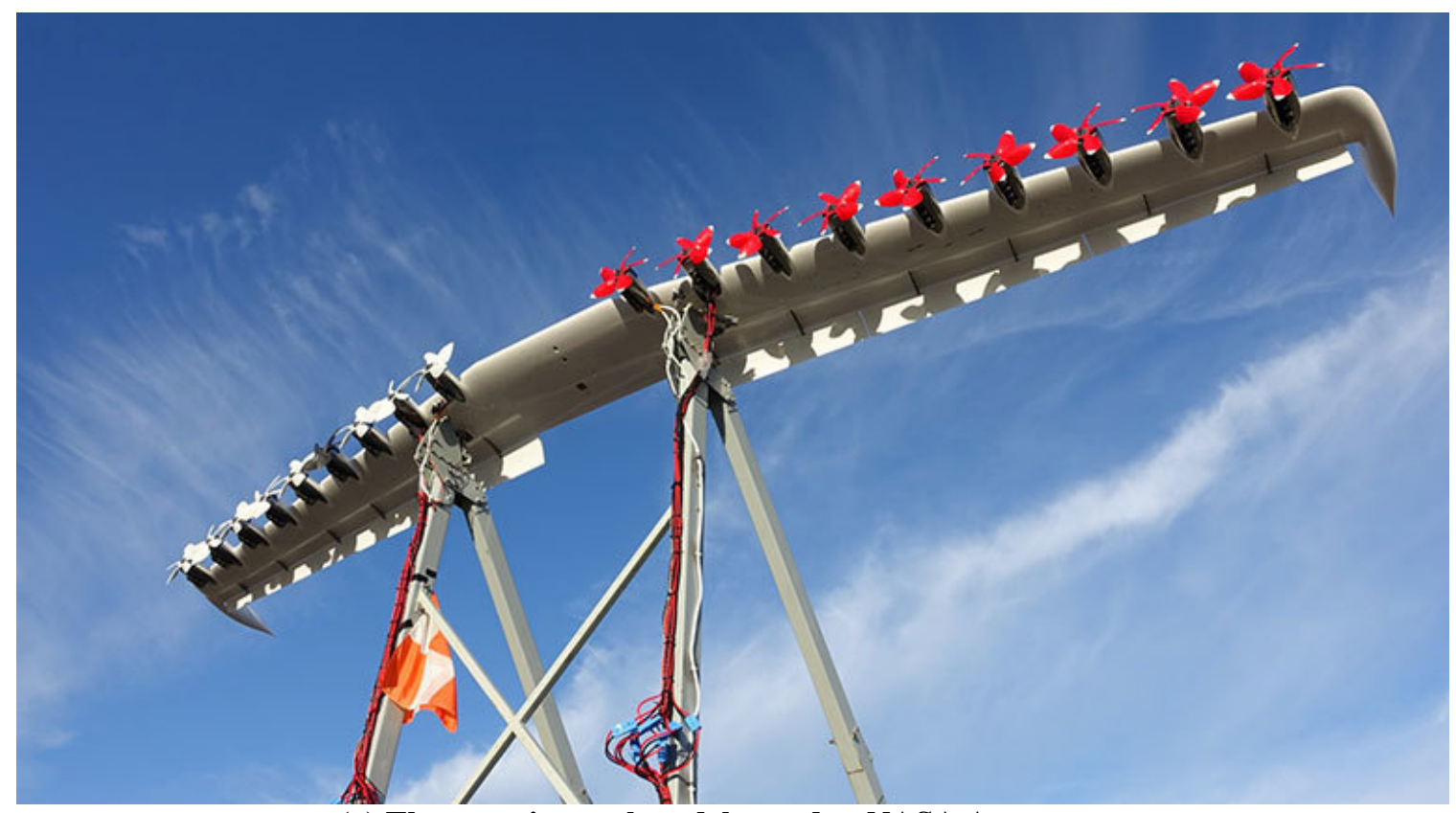

(a) The experimental model tested at NASA Armstrong.

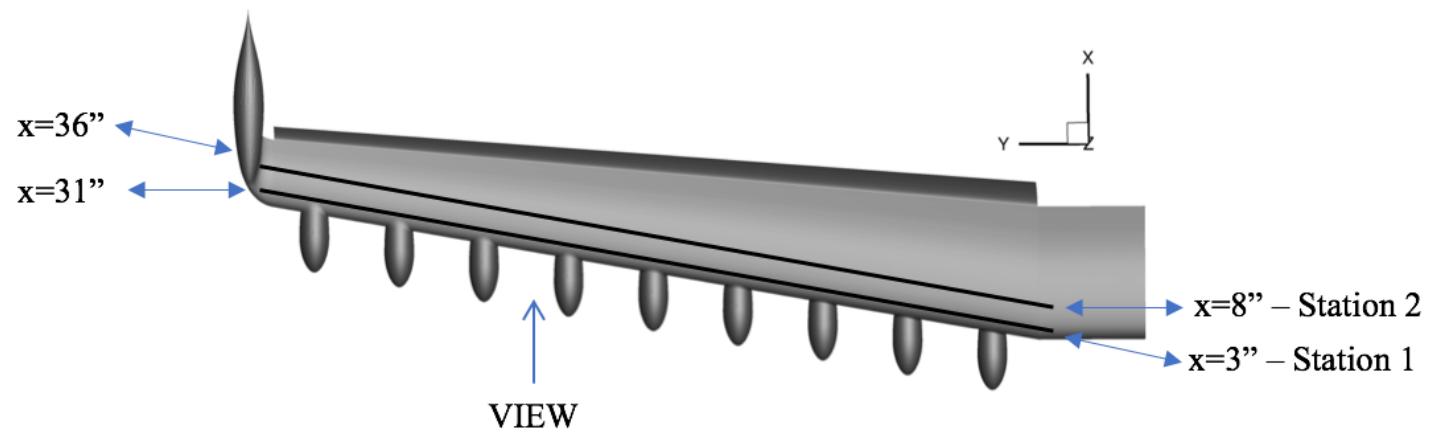

(b) The computational model of the right semispan DEP wing with $40^{\circ}$ flap setting.

Figure 3. The DEP wing test on the Hybrid-Electric Integrated Systems Testbed (HEIST) truck. 
Denver, CO

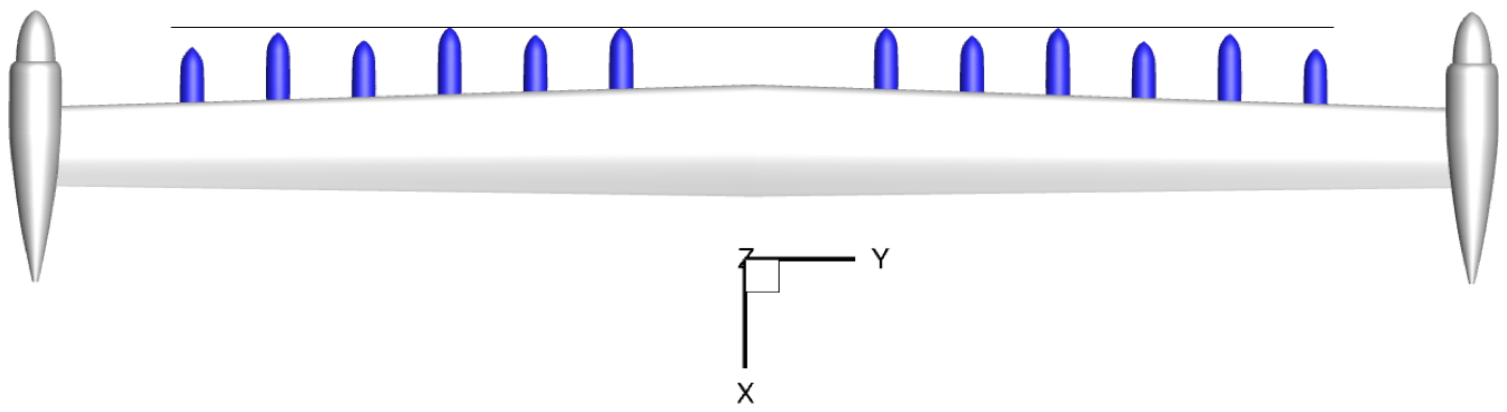

(a) cruise wing with tip nacelles, high-lift nacelles (blue) with black alignment line to emphasize the staggered pattern of the nacelles

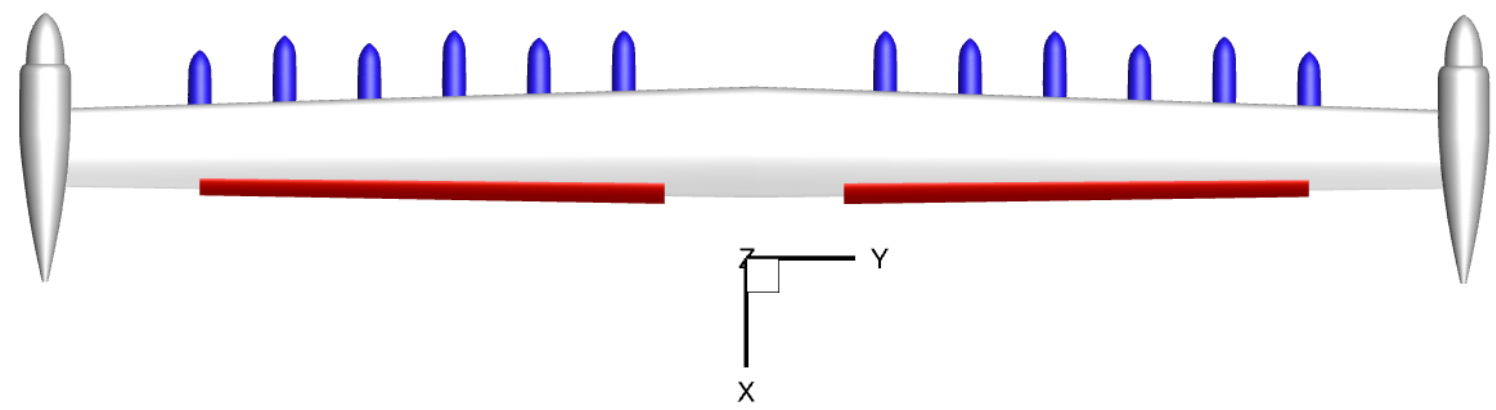

(b) wing with tip nacelles, $30^{\circ}$ flap (red), high-lift nacelles (blue)

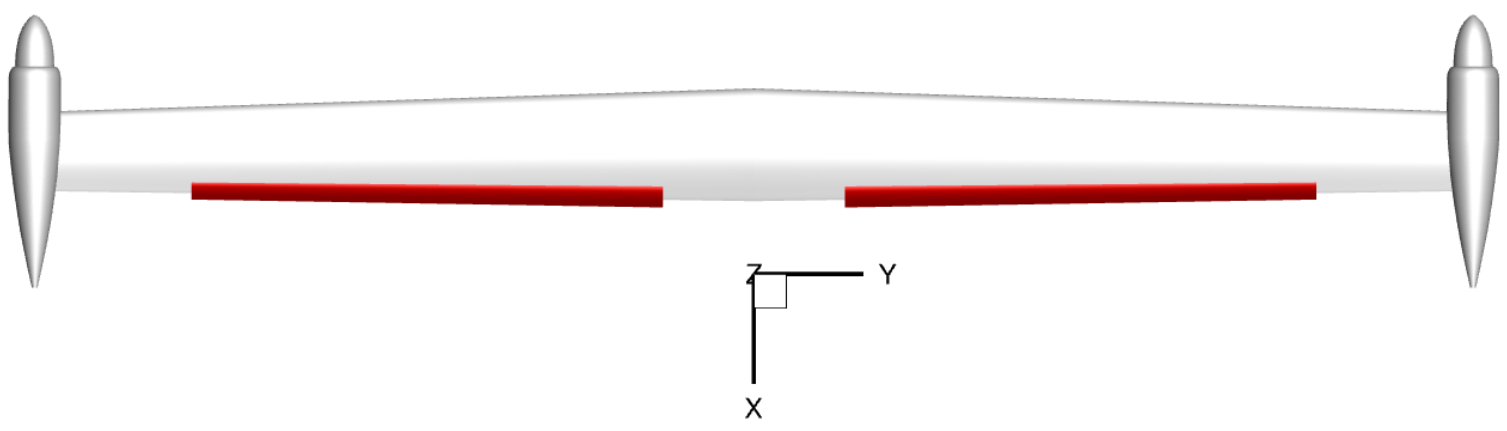

(c) wing with tip nacelles, $30^{\circ}$ flap (red), no high-lift nacelles

Figure 4. The wing configurations for the X-57 Maxwell airplane. 


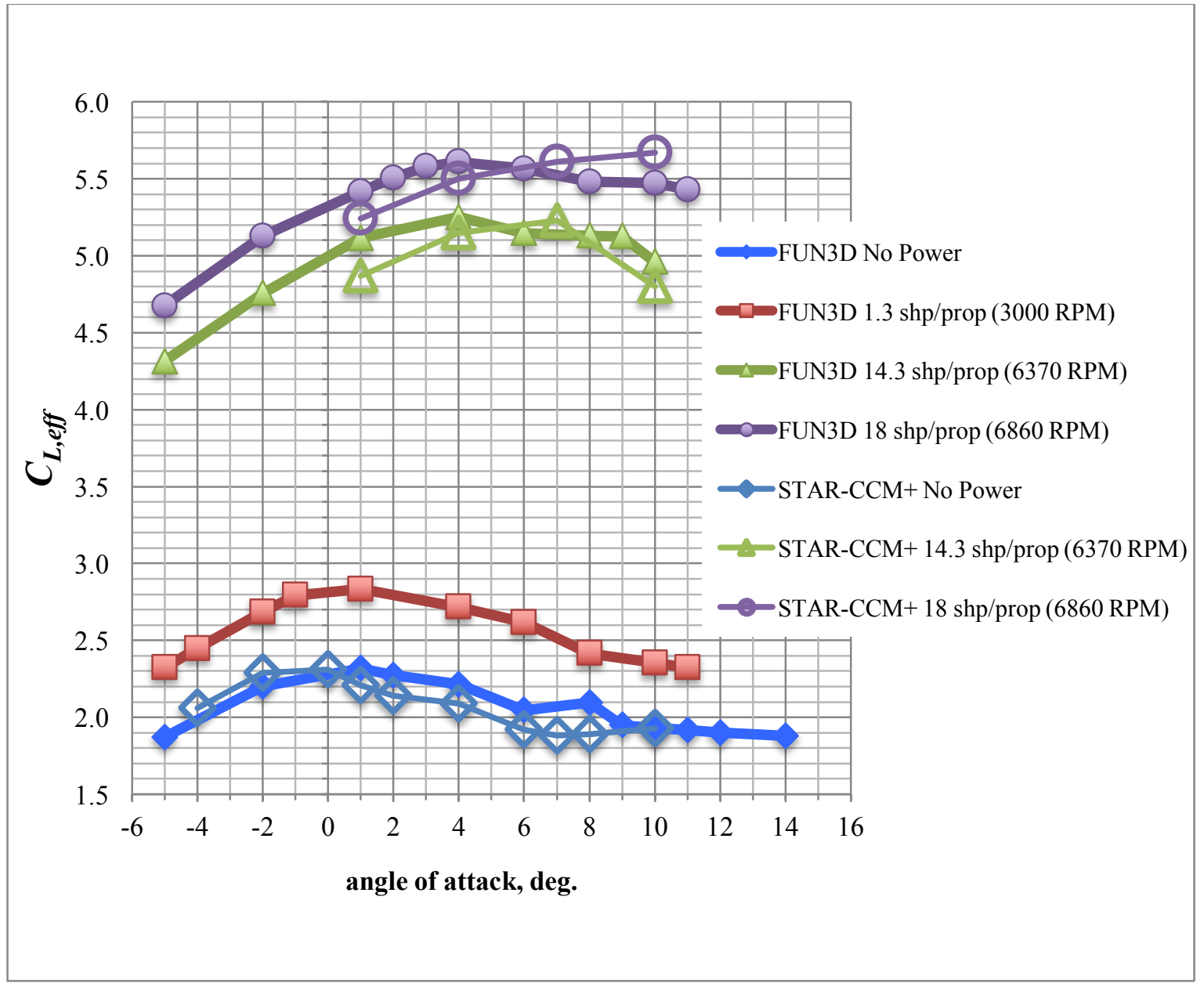

Figure 5. Comparisons of effective lift coefficient between FUN3D and STAR-CCM+ for the LEAPTech wing with $40^{\circ}$ flap at $73 \mathrm{mph}, T=40^{\circ} \mathrm{F}, \mathrm{h}=2300 \mathrm{ft}$, and $\mathrm{Re}=1.07 \mathrm{million}$. 


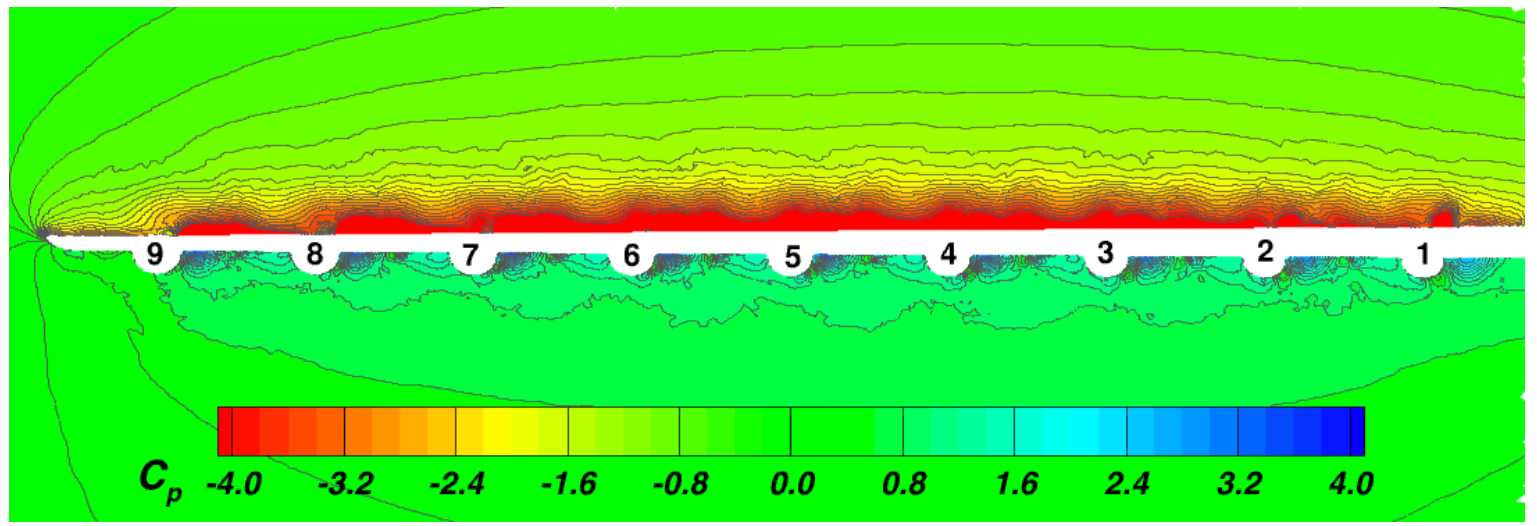

(a) $\quad \alpha=4^{\circ}$

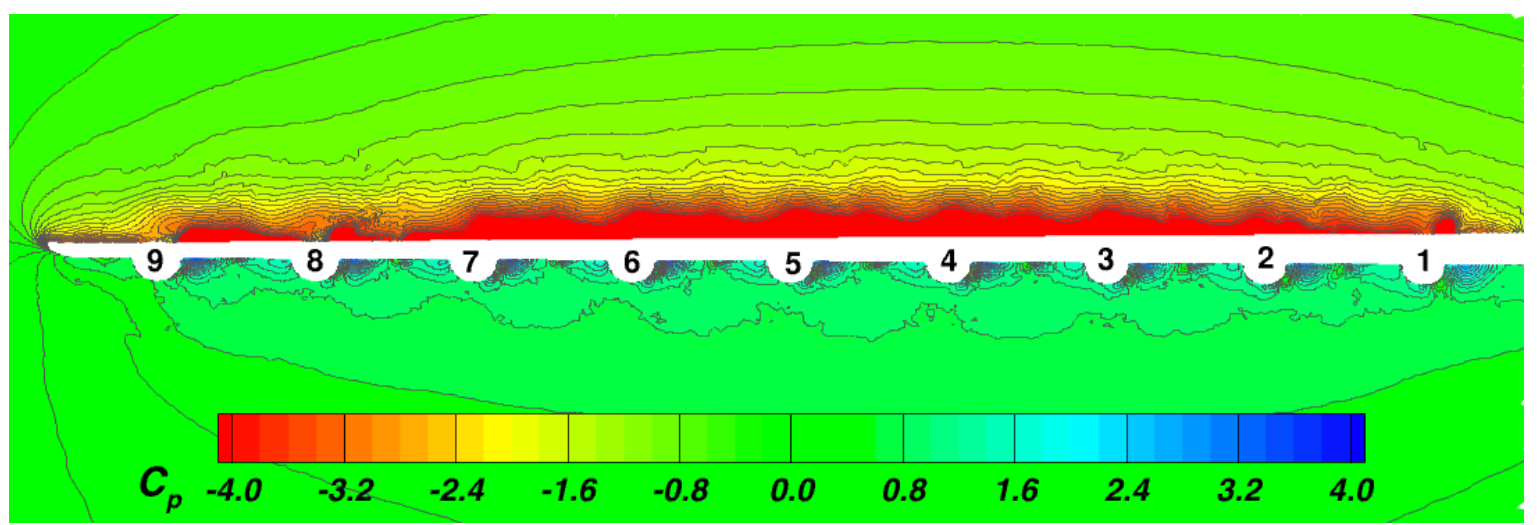

(b) $\quad \alpha=8^{\circ}$

Figure 6. Pressure coefficient from FUN3D at station 1 of the LEAPTech wing with $40^{\circ}$ flap at 73 $\mathrm{mph}, \mathrm{T}=40^{\circ} \mathrm{F}, \mathrm{h}=2300 \mathrm{ft}$, and $\mathrm{Re}=1.07 \mathrm{million}$, and $18 \mathrm{shp} / \mathrm{prop}(6860 \mathrm{RPM})$. 
Denver, CO

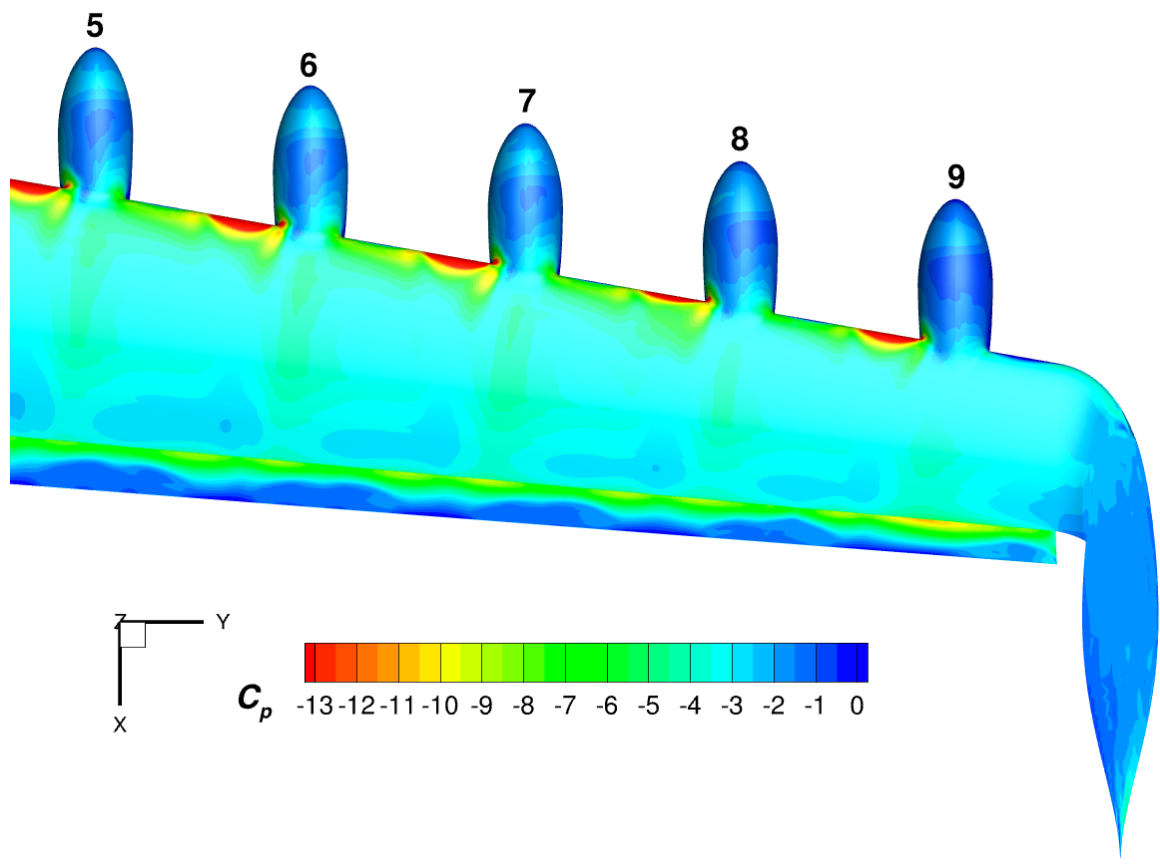

(a) $\quad \alpha=4^{\circ}$

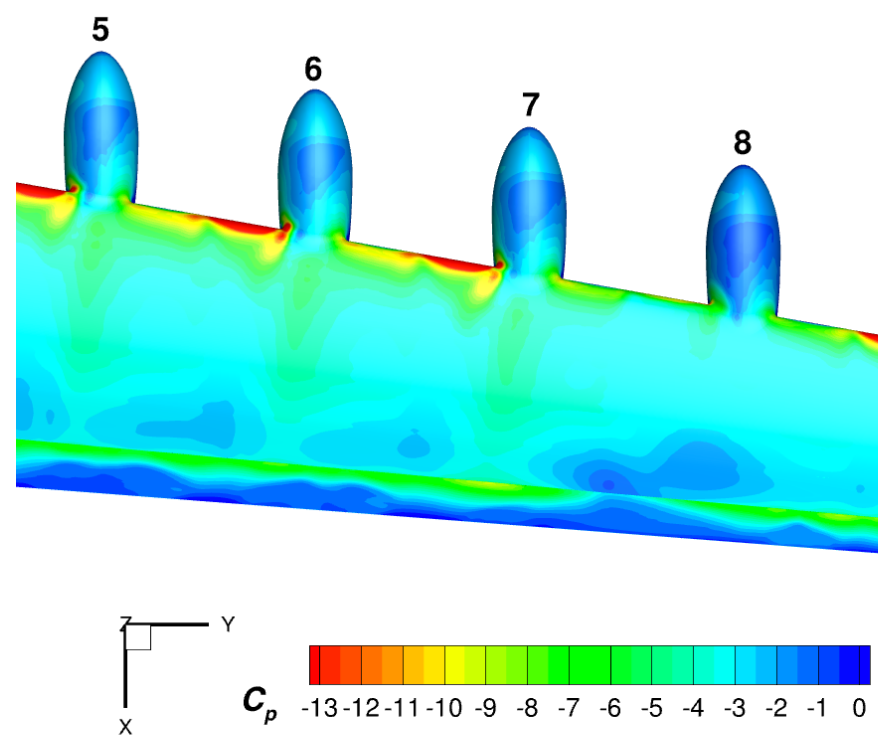

(b) $\quad \alpha=8^{\circ}$

Figure 7. Pressure coefficient from FUN3D on the outboard, upper surface of the LEAPTech wing with $40^{\circ}$ flap at $73 \mathrm{mph}, \mathrm{T}=40^{\circ} \mathrm{F}, \mathrm{h}=2300 \mathrm{ft}$, and $\mathrm{Re}=1.07 \mathrm{million}$, and $18 \mathrm{shp} / \mathrm{prop}$ (6860 RPM). 


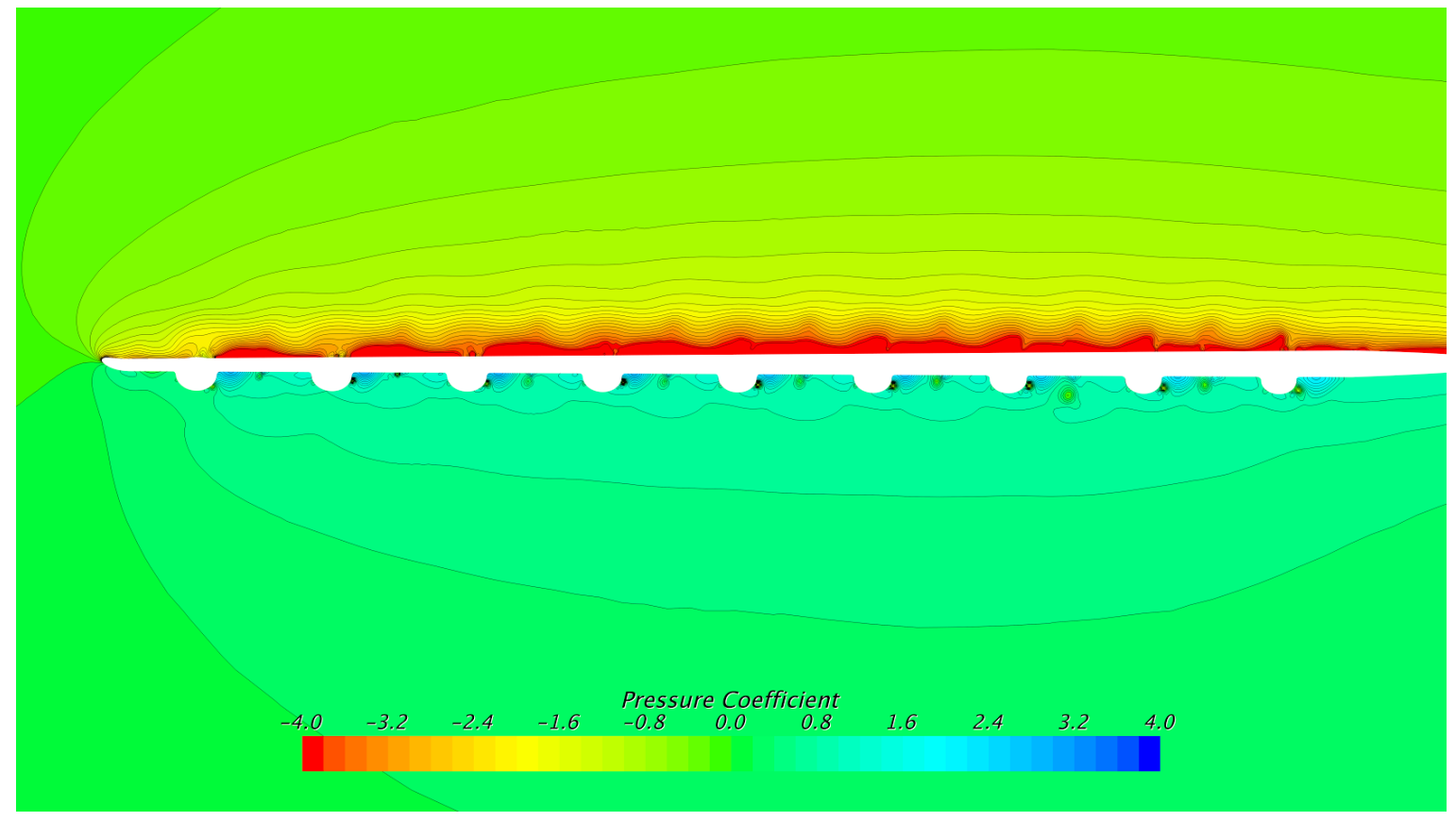

(a) $\alpha=4^{\circ}$

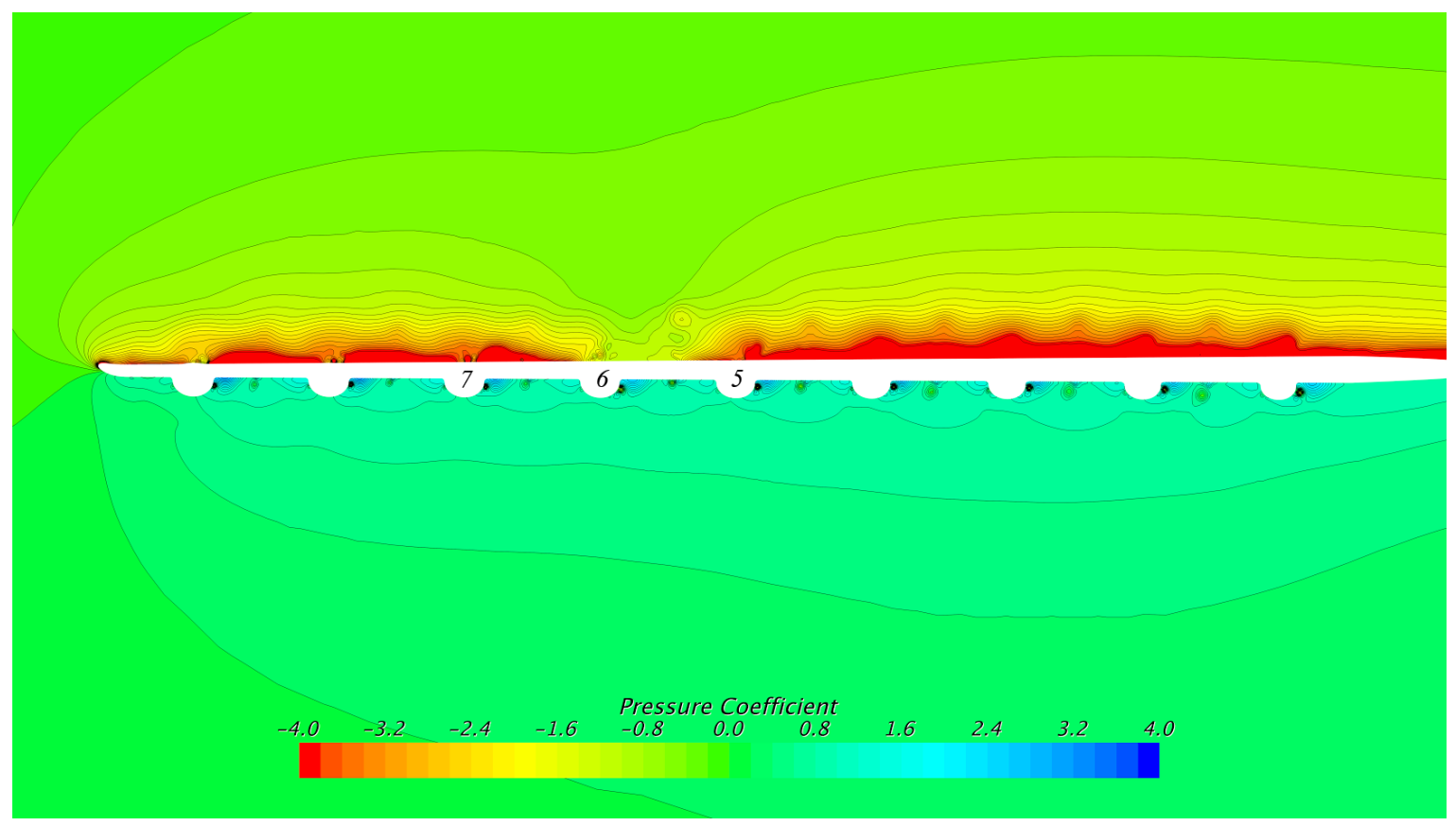

(b) $\alpha=10^{\circ}$

Figure 8. Pressure coefficient from STAR-CCM+ at station 1 of the LEAPTech wing with $40^{\circ}$ flap at $73 \mathrm{mph}, \mathrm{T}=40^{\circ} \mathrm{F}, \mathrm{h}=2300 \mathrm{ft}$, and $\mathrm{Re}=1.07 \mathrm{million}$, and $14.3 \mathrm{shp} / \mathrm{prop}(6370 \mathrm{RPM})$. 
Denver, CO

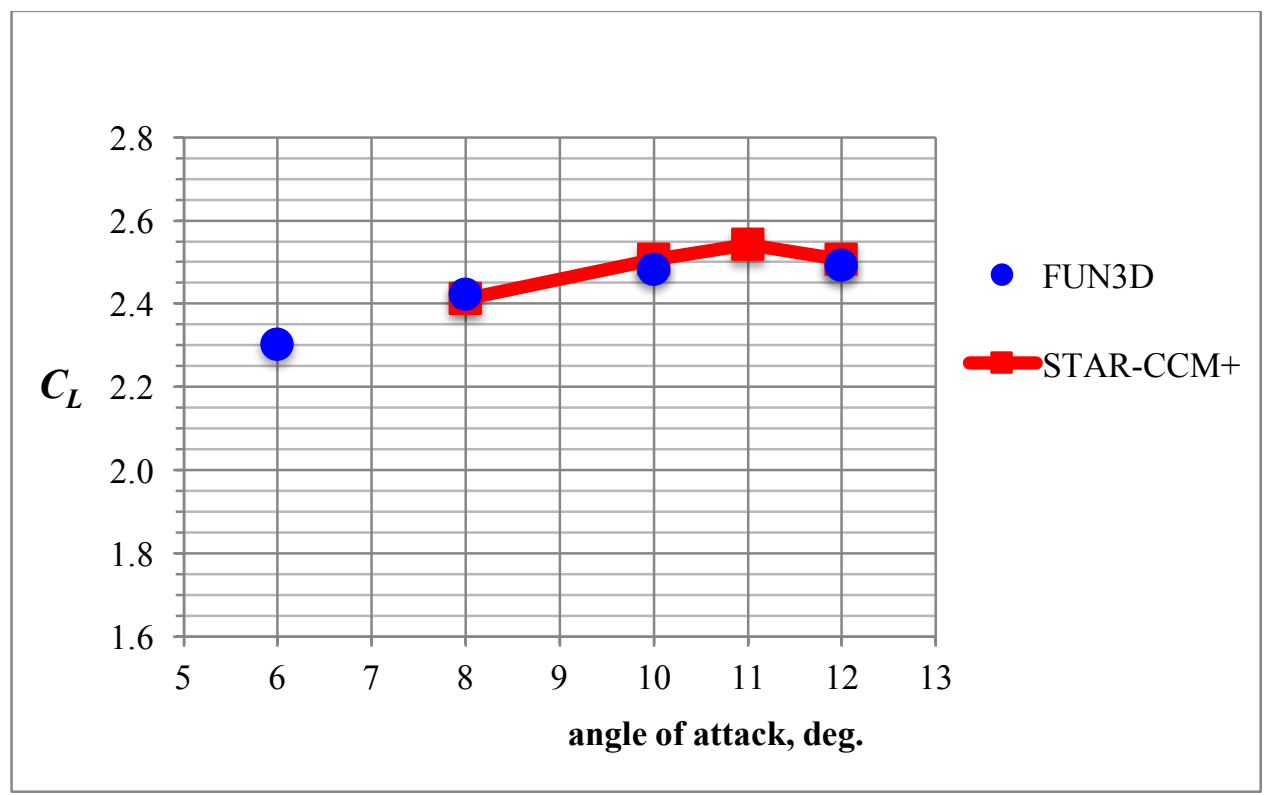

(a) Lift coefficient

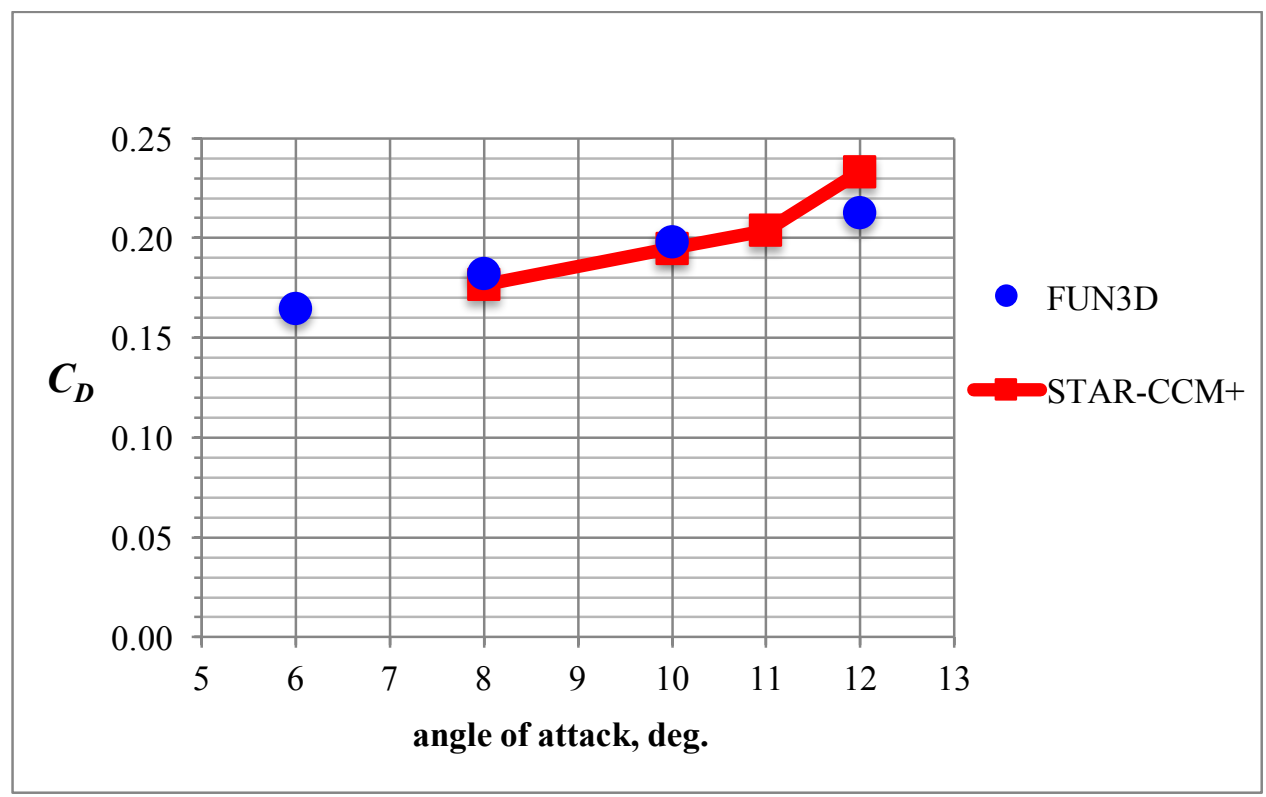

(b) Drag coefficient

Figure 9. The comparison of lift and drag coefficient between FUN3D SARC+QCR and STARCCM+ SST Menter $k-\omega$ with $\gamma-\mathrm{Re}_{\theta}$ transition model for the unblown $\mathrm{X}-57,3^{\circ}$ flap configuration with tip nacelles but no high-lift nacelles, $58 \mathrm{KTAS}, \mathrm{T}=59^{\circ} \mathrm{F}, \mathrm{h}=0 \mathrm{ft}$, and $\mathrm{Re}=1.33$ million. 


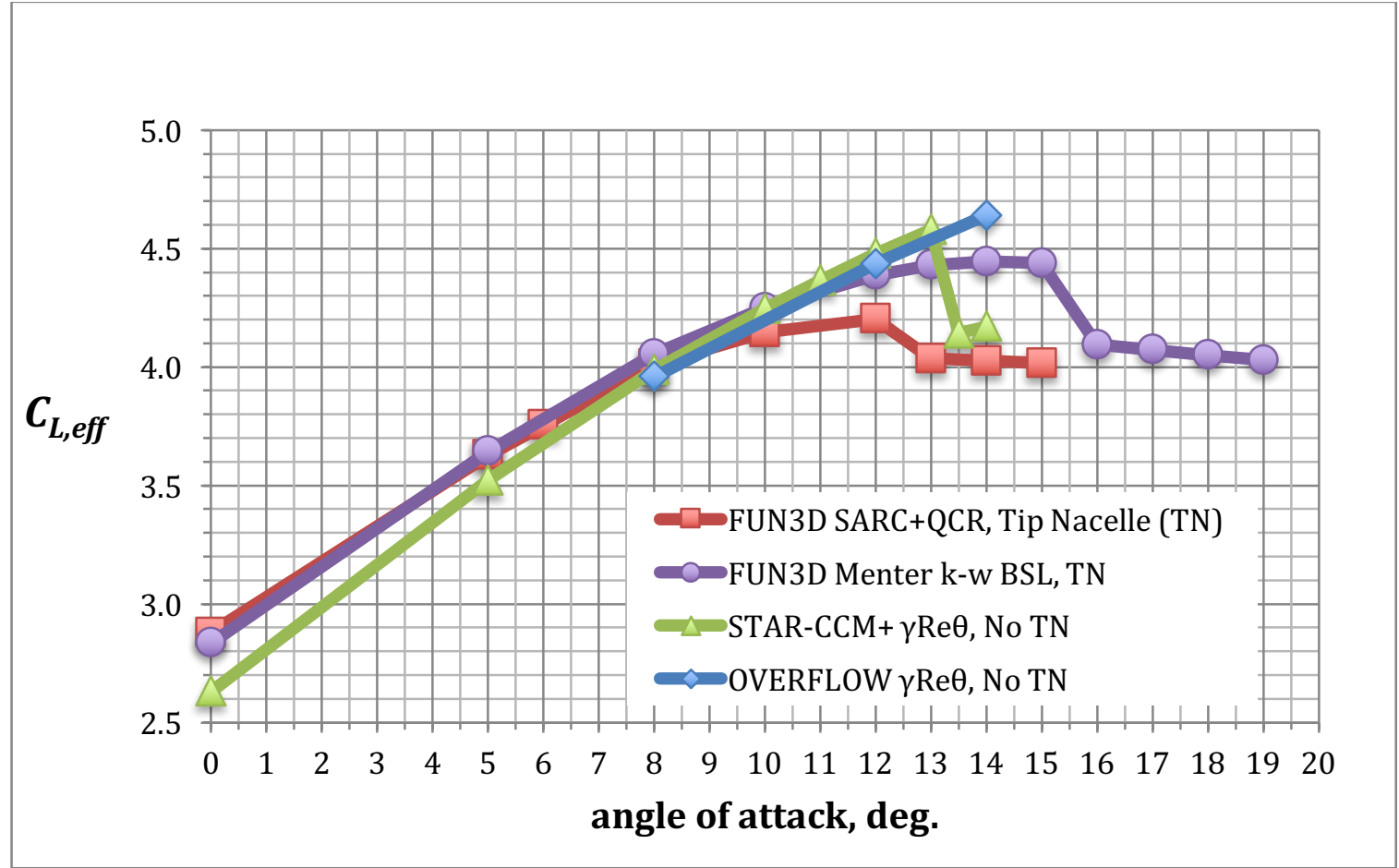

(a)

Effective lift coefficient

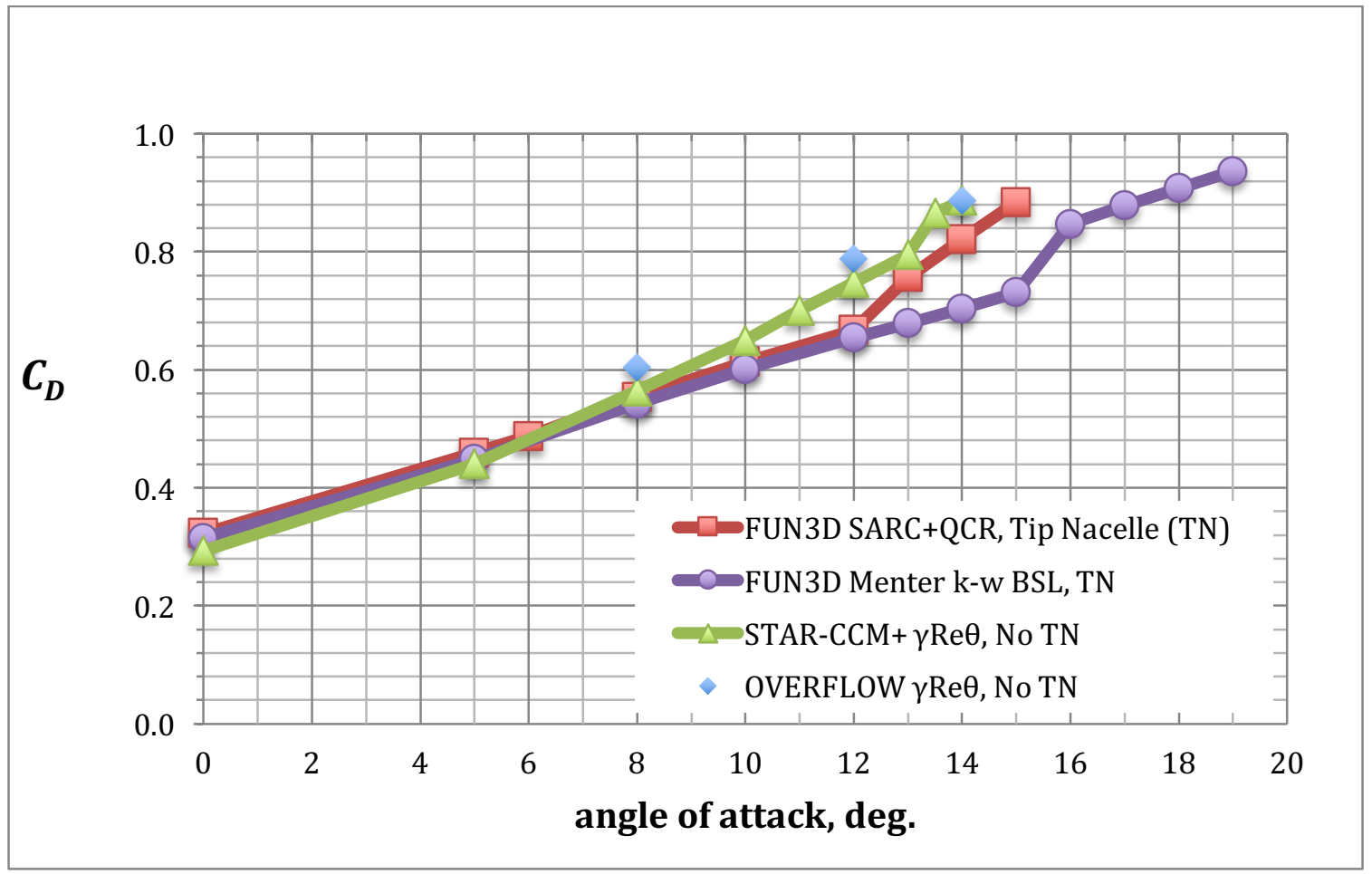

(b) Drag coefficient

Figure 10. The comparison of effective lift coefficient and drag coefficient for the X-57 blown wing with $30^{\circ}$ flap and high-lift nacelles, $58 \mathrm{KTAS}, \mathrm{T}=59^{\circ} \mathrm{F}, \mathrm{h}=0 \mathrm{ft}$, and $\mathrm{Re}=1.33 \mathrm{million}$. 


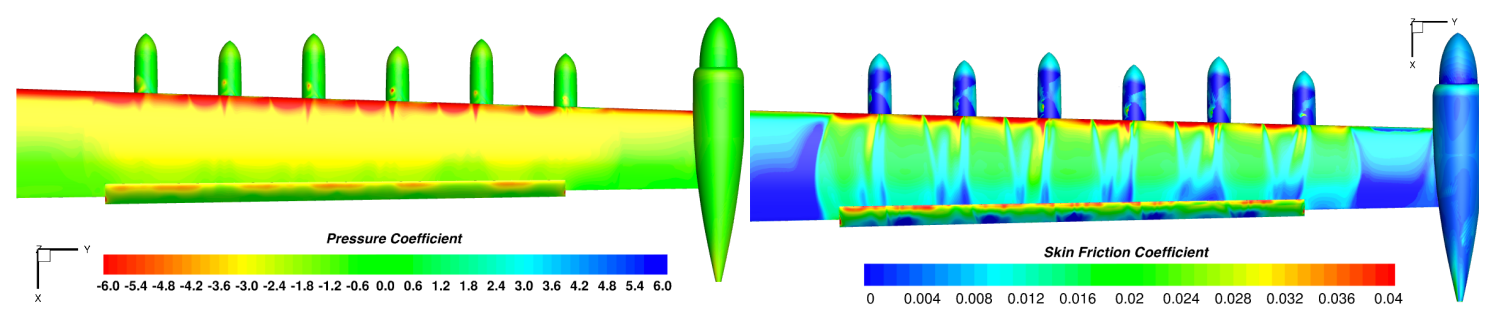

(a) FUN3D SARC+QCR, $C_{L, e f f}=4.202$

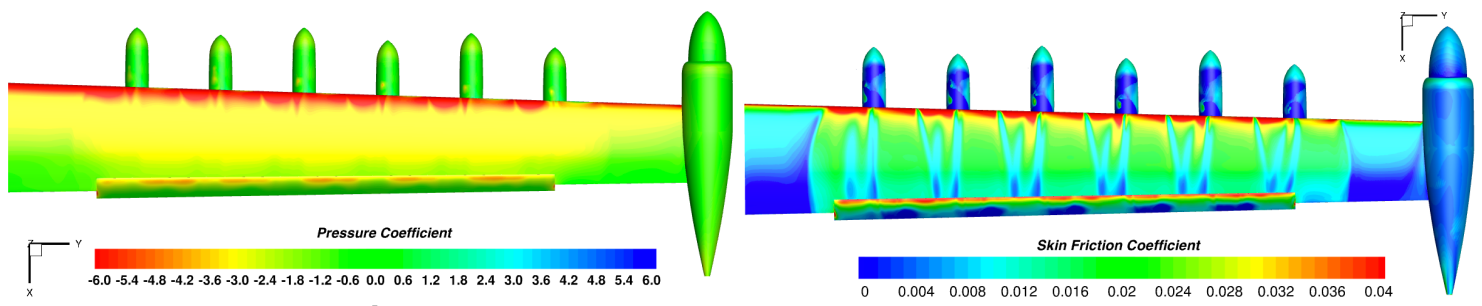

(b) FUN3D Menter $k$ - $\omega$ BSL, $C_{L, e f f}=4.388$
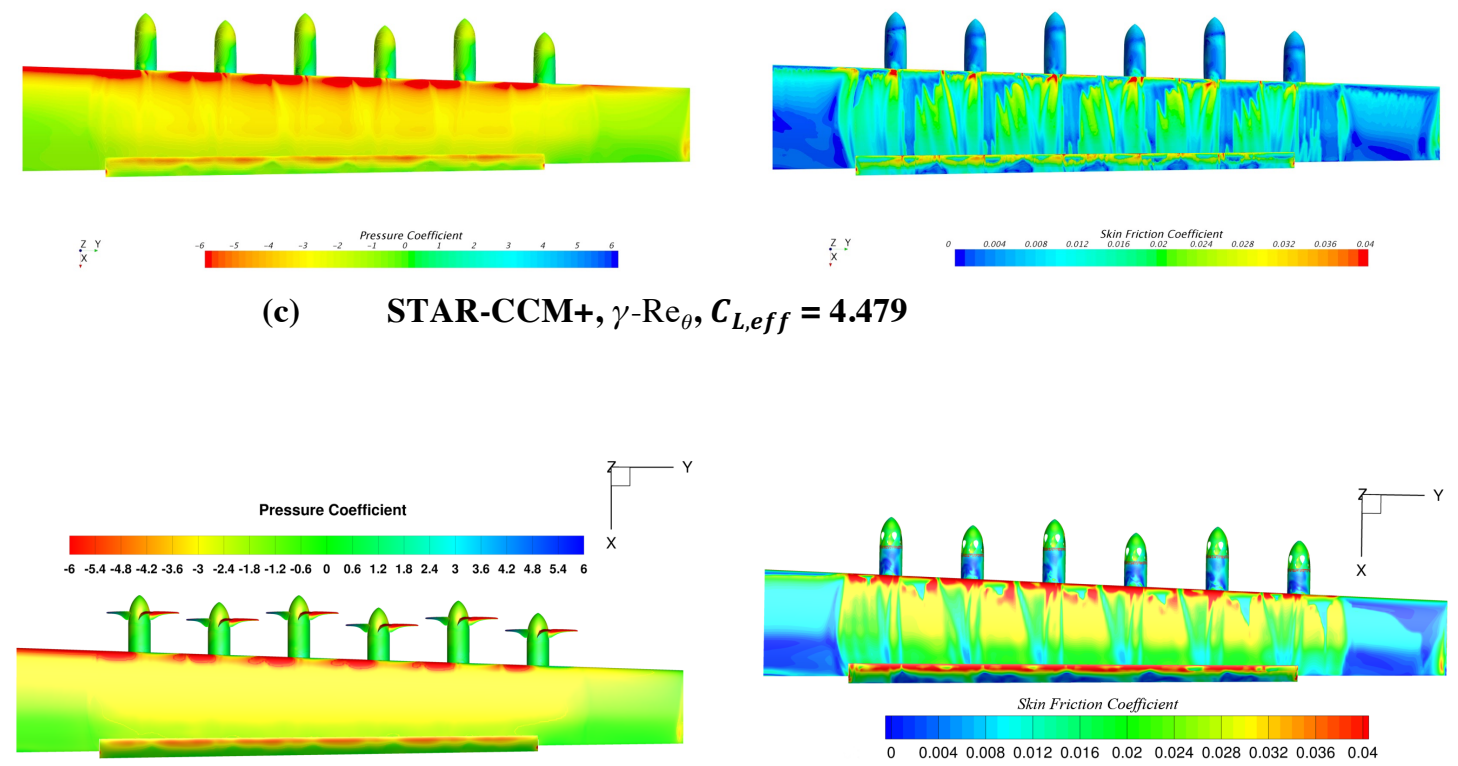

(d) OVERFLOW, $\gamma-\operatorname{Re}_{\theta}, C_{L, e f f}=4.435$

Figure 11. The comparison of upper-surface pressure coefficient (left) and skin friction coefficient (right) for the $\mathrm{X}-57$ blown wing with $30^{\circ}$ flap and high-lift nacelles, $\alpha=12^{\circ}, 58 \mathrm{KTAS}, \mathrm{T}=59^{\circ} \mathrm{F}, \mathrm{h}=0 \mathrm{ft}$, and $\operatorname{Re}=\mathbf{1 . 3 3}$ million. 


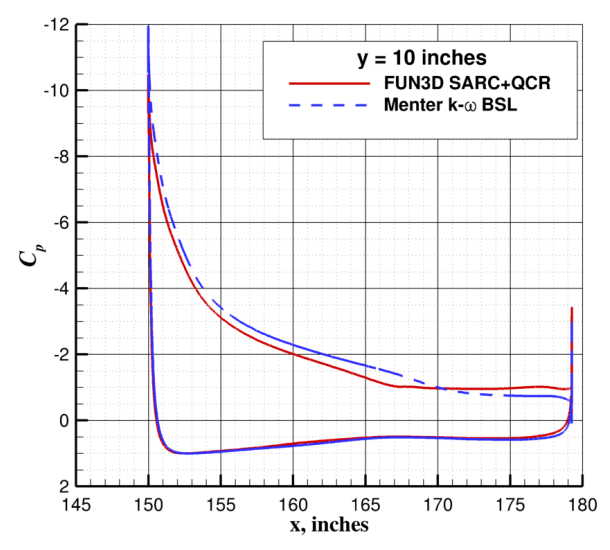

(a) $\mathbf{y}=\mathbf{1 0}$ inches

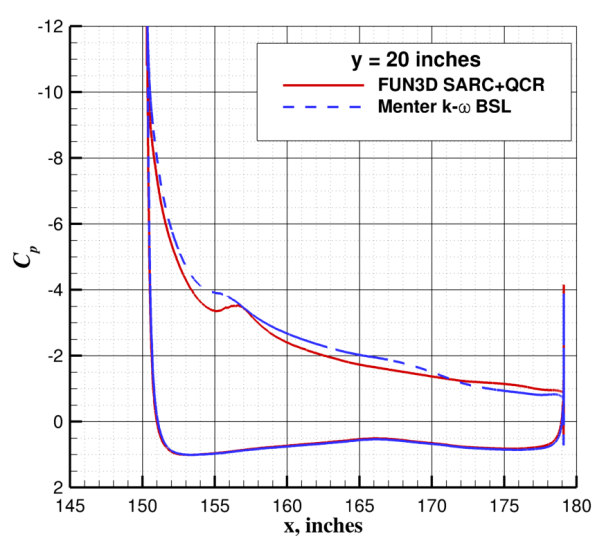

(b) $\mathbf{y}=\mathbf{2 0}$ inches

Figure 12. The comparison of pressure coefficient between the FUN3D SARC+QCR and Menter $k$ - $\omega$ BSL solutions for the $\mathrm{X}-57$ blown wing with $30^{\circ}$ flap and high-lift nacelles, $\alpha=12^{\circ}, 58 \mathrm{KTAS}, \mathrm{T}=59^{\circ} \mathrm{F}$, $\mathrm{h}=0 \mathrm{ft}$, and $\mathrm{Re}=1.33$ million.

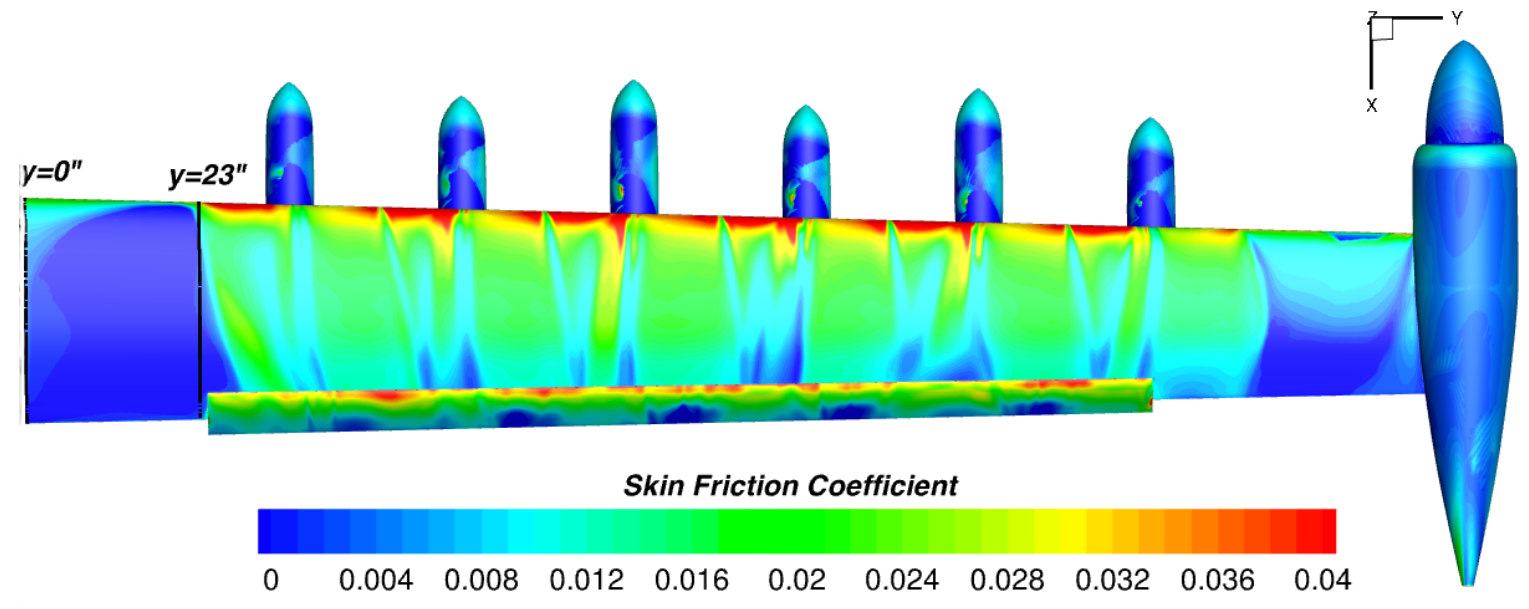

Figure 13. The upper-surface skin friction coefficient for the $\mathrm{X}-57$ blown wing with $30^{\circ}$ flap and high-lift nacelles, $\alpha=13^{\circ}, 58 \mathrm{KTAS}, \mathrm{T}=59^{\circ} \mathrm{F}, \mathrm{h}=0 \mathrm{ft}$, and $\mathrm{Re}=1.33$ million. FUN3D SARC+QCR 

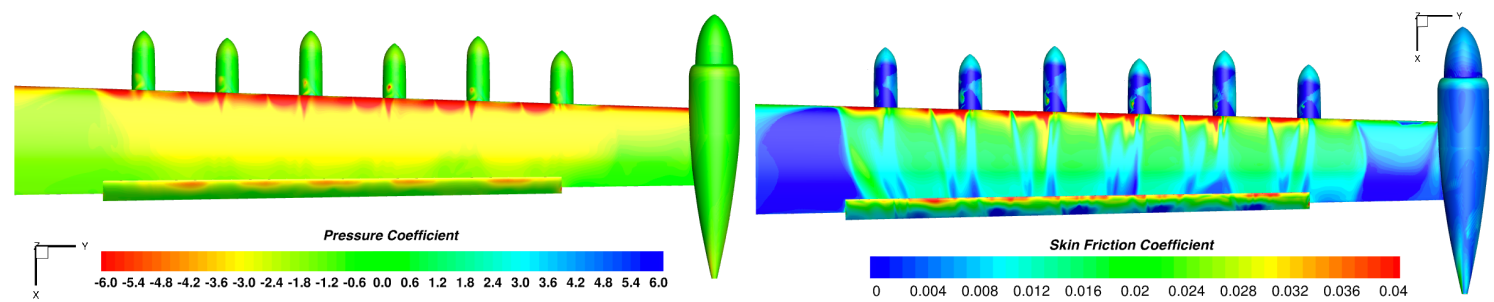

(a) FUN3D SARC+QCR, $C_{L, e f f}=4.026$
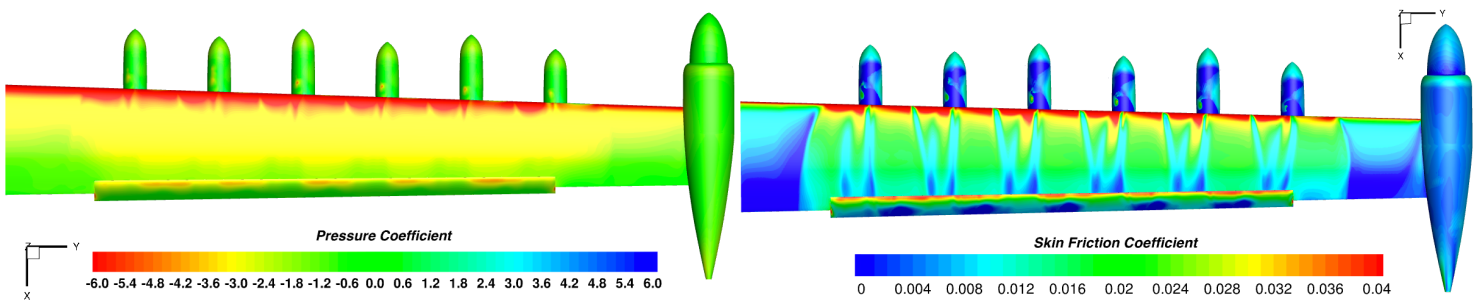

(b)

FUN3D Menter $k$ - $\omega$ BSL, $C_{L, e f f}=4.444$
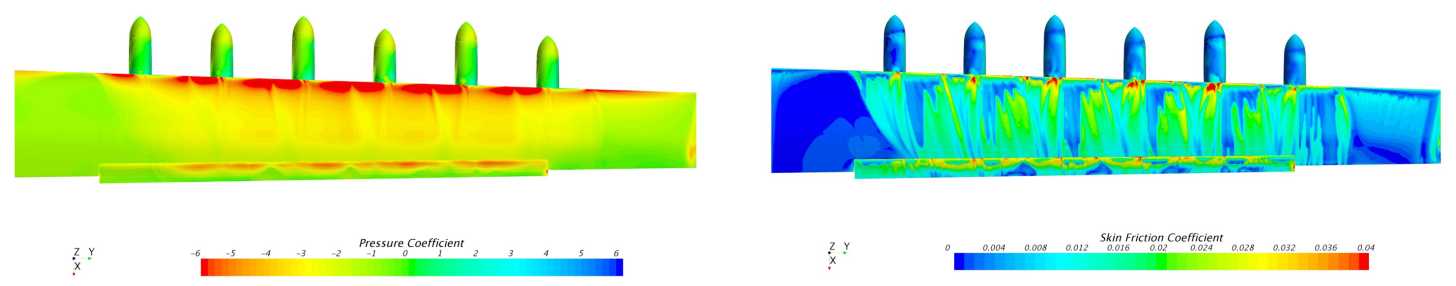

(c) STAR-CCM+, $\gamma-\mathrm{Re}_{\theta}, C_{L, e f f}=4.170$
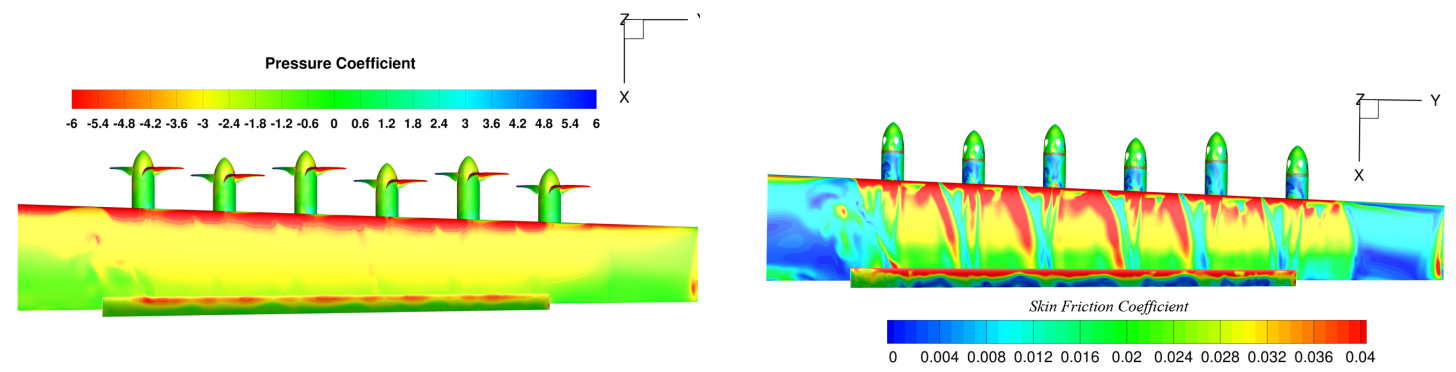

(d) OVERFLOW, $\gamma-\operatorname{Re}_{\theta}, C_{L, e f f}=4.64$

Figure 14. The comparison of upper-surface pressure coefficient (left) and skin friction coefficient (right) for the $\mathrm{X}-57$ blown wing with $30^{\circ}$ flap and high-lift nacelles at $\alpha=14^{\circ}, 58 \mathrm{KTAS}, \mathrm{T}=59^{\circ} \mathrm{F}, \mathrm{h}=0$ $\mathrm{ft}$, and $\mathrm{Re}=1.33$ million. 


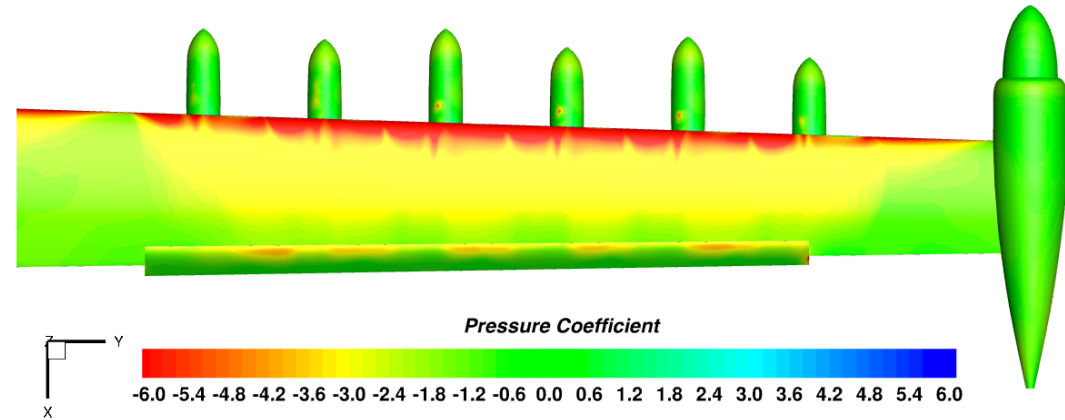

(a) Pressure coefficient

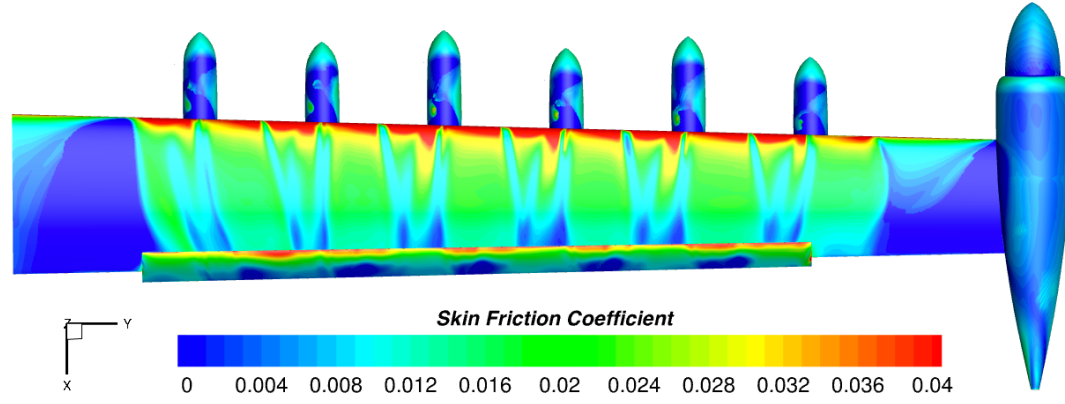

(b) Skin friction coefficient

Figure 15. The FUN3D Menter $k-\omega$ BSL solution for the $X-57$ blown wing with $30^{\circ}$ flap, tip nacelle and high-lift nacelles at $\alpha=16^{\circ}\left(C_{L, e f f}=4.095\right), 58 \mathrm{KTAS}, \mathrm{T}=59^{\circ} \mathrm{F}, \mathrm{h}=0 \mathrm{ft}$, and $\mathrm{Re}=1.33$ million.

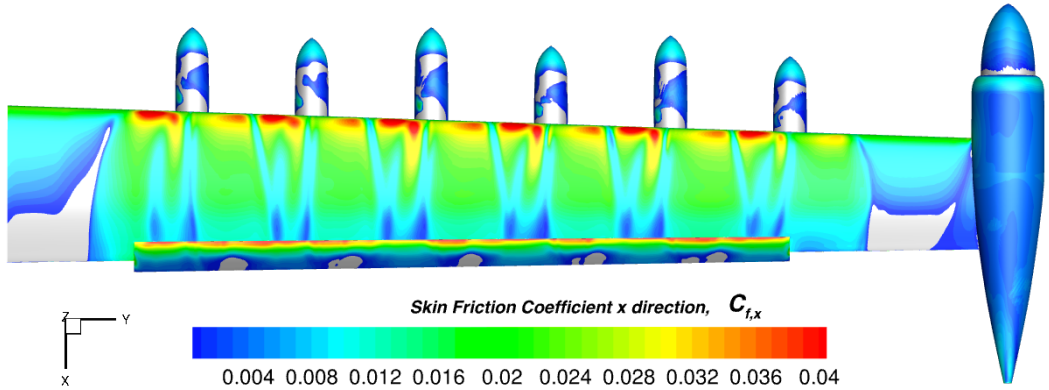

(a) $\alpha=14^{\circ}$

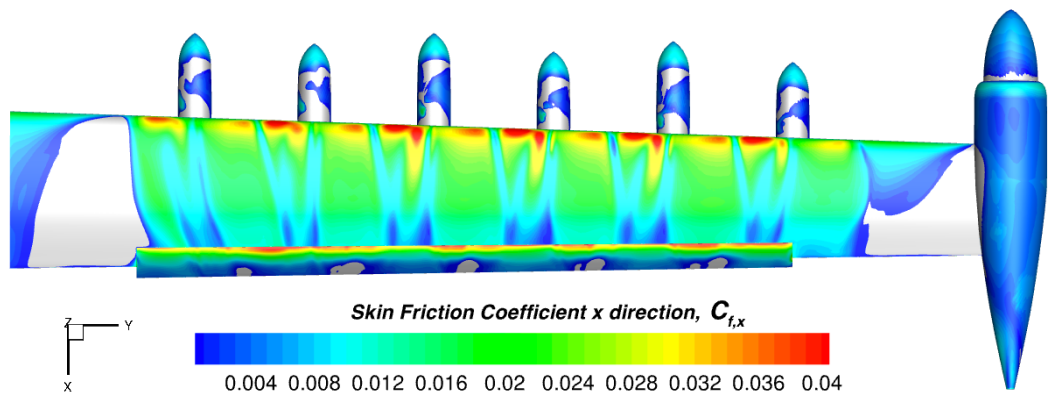

(b) $\alpha=16^{\circ}$

Figure 16. The skin friction coefficient in $\mathrm{x}$ direction (values of $C_{f, x}<0$ are cut from view) for FUN3D Menter $k$ - $\omega$ BSL solutions for the X-57 blown wing with $30^{\circ}$ flap, tip nacelle and high-lift nacelles at $58 \mathrm{KTAS}, \mathrm{T}=59^{\circ} \mathrm{F}, \mathrm{h}=0 \mathrm{ft}$, and $\mathrm{Re}=1.33$ million. 


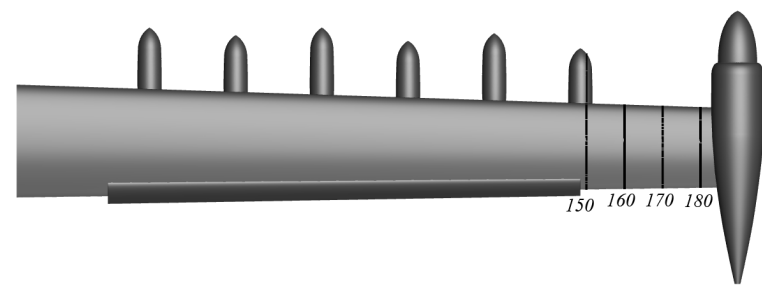

(a) span locations

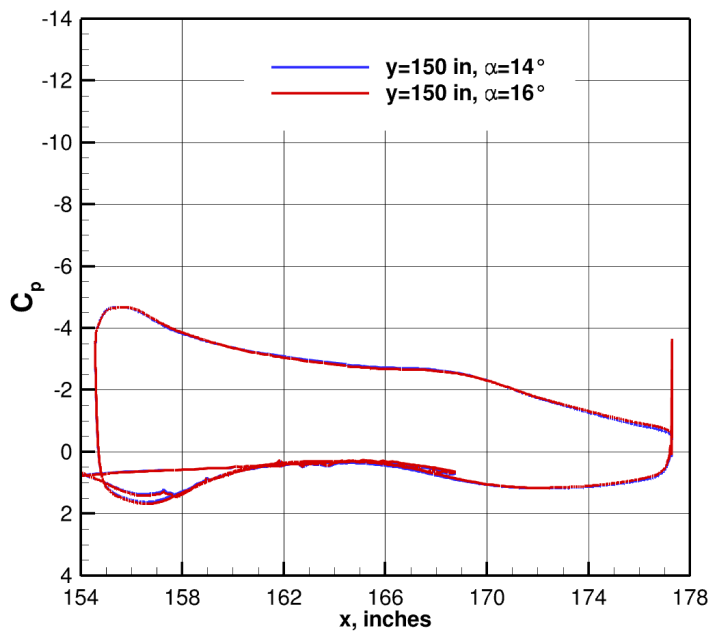

(b) $\mathbf{y}=\mathbf{1 5 0}$ in.

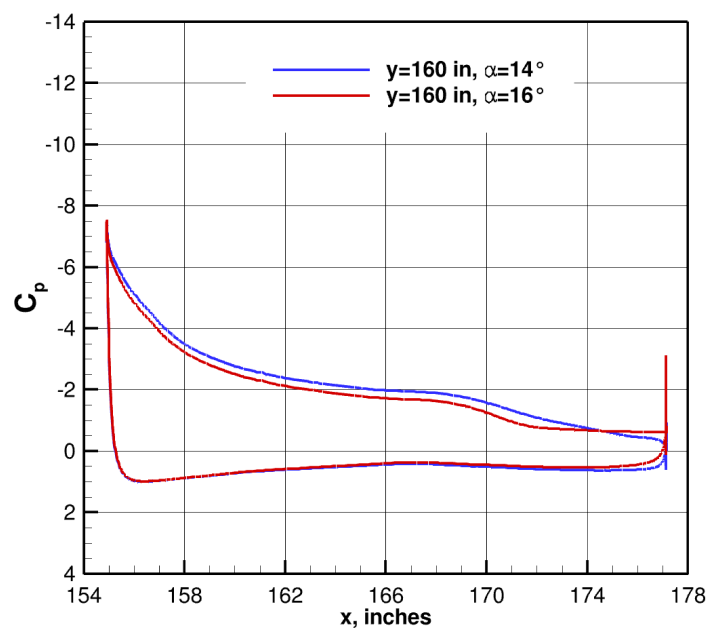

(c) $y=160$ in.

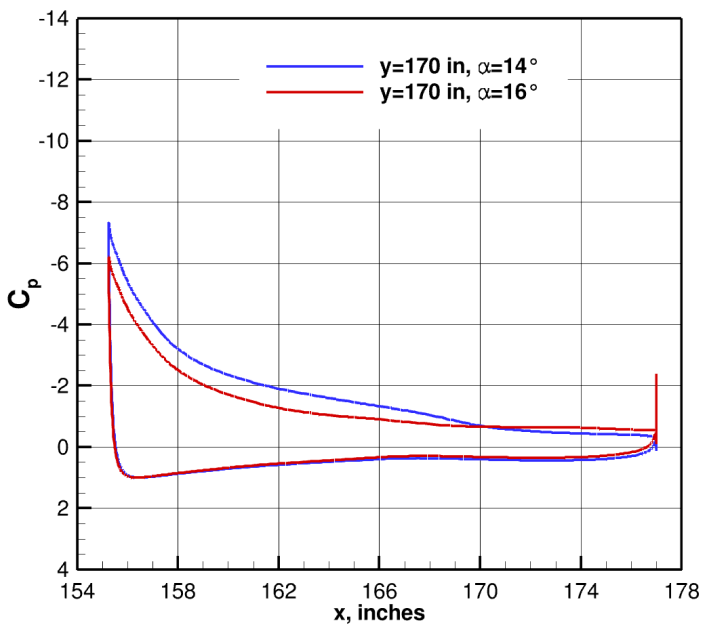

(d) $\mathbf{y}=\mathbf{1 7 0}$ in.

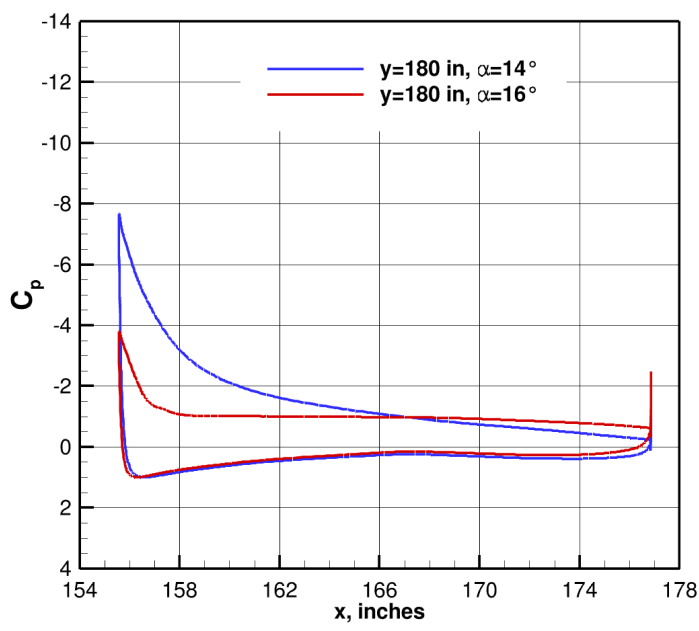

(e) $y=180$ in.

Figure 17. The comparison of pressure coefficient between $\alpha=14^{\circ}$ and $\alpha=16^{\circ}$ at outboard span locations for FUN3D Menter $k-\omega$ BSL solutions for the X-57 blown wing with $30^{\circ}$ flap, tip nacelle and high-lift nacelles at $58 \mathrm{KTAS}, \mathrm{T}=59^{\circ} \mathrm{F}, \mathrm{h}=0 \mathrm{ft}$, and $\mathrm{Re}=1.33$ million. 